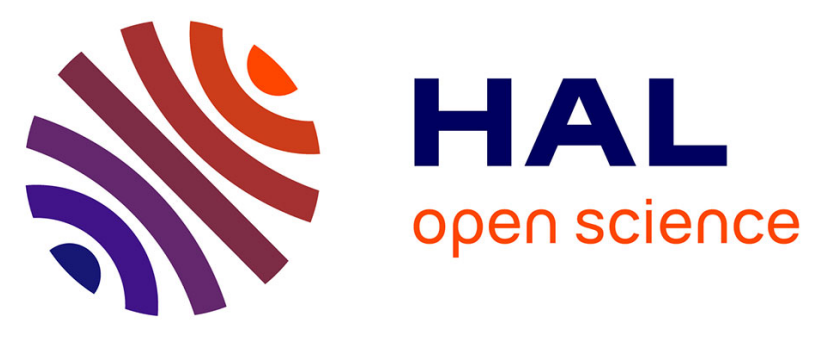

\title{
Heat transfer intensification by low or high frequency ultrasound: Thermal and hydrodynamic phenomenological analysis
}

Odin Bulliard-Sauret, Jérémy Berindei, Sébastien Ferrouillat, Laure Vignal, Alain Memponteil, Christophe Poncet, Jean Marc Leveque, Nicolas Gondrexon

\section{To cite this version:}

Odin Bulliard-Sauret, Jérémy Berindei, Sébastien Ferrouillat, Laure Vignal, Alain Memponteil, et al.. Heat transfer intensification by low or high frequency ultrasound: Thermal and hydrodynamic phenomenological analysis. Experimental Thermal and Fluid Science, 2019, 104, pp.258-271. 10.1016/j.expthermflusci.2019.03.003 . hal-02063257

\section{HAL Id: hal-02063257 \\ https://hal.science/hal-02063257}

Submitted on 22 Oct 2021

HAL is a multi-disciplinary open access archive for the deposit and dissemination of scientific research documents, whether they are published or not. The documents may come from teaching and research institutions in France or abroad, or from public or private research centers.
L'archive ouverte pluridisciplinaire HAL, est destinée au dépôt et à la diffusion de documents scientifiques de niveau recherche, publiés ou non, émanant des établissements d'enseignement et de recherche français ou étrangers, des laboratoires publics ou privés.

\section{(ㄷ)(1) $\$$}

Distributed under a Creative Commons Attribution - NonCommercial| 4.0 International 


\section{Heat transfer intensification by low or high frequency ultrasound:}

\section{2 thermal and hydrodynamic phenomenological analysis}

3 O. Bulliard-Sauret ${ }^{a, b^{*}}$, J. Berindei ${ }^{a}$, S. Ferrouillat ${ }^{a, c}$, L. $_{\text {. }}$ Vignal $^{a}$, A.

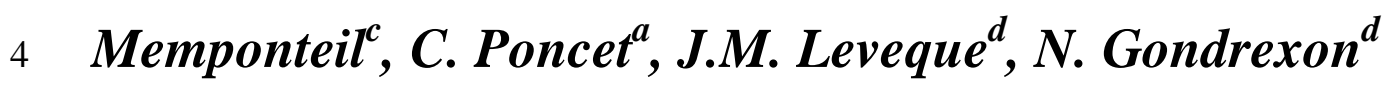

5

${ }^{\text {a } U n i v e r s i t e ́ ~ G r e n o b l e-A l p e s, ~ C N R S, ~ G r e n o b l e ~ I N P, ~ L E G I, ~ F-38000 ~ G r e n o b l e, ~ F r a n c e ~}$

${ }^{\mathrm{b}}$ Université de Lille, Yncréa-HEI, 13 Rue de Toul, F-59014 Lille, France

${ }^{c}$ Université Grenoble-Alpes, CEA-LITEN, 17 Rue des Martyrs, F-38000 Grenoble, France

${ }^{\mathrm{d}}$ Université Grenoble-Alpes, CNRS, Grenoble INP, LRP, 38000 Grenoble, France

*Corresponding author: odin.bulliard-sauret@yncrea.fr

\section{Abstract}

The aim of this work is to quantitatively demonstrate the intensification of heat transfer in forced convection by mean of ultrasonic irradiation at low $(25 \mathrm{kHz})$ or high $(2 \mathrm{MHz})$ frequency. High frequency ultrasound induces convective acoustic streaming while low frequency ultrasonic waves produce mainly cavitation effects. These hydrodynamic phenomena are at the origin of strongly different observations in terms of flow pattern modification and thereby in Nusselt number values. A link is tentatively established between hydrodynamic behaviors at both ultrasonic frequencies and corresponding thermal results. Hydrodynamic approach was performed with a 2D-2C PIV device while thermal one was carried out under uniform heat flux conditions. It seems that thermal enhancement effect of acoustic streaming ( $2 \mathrm{MHz}$ ) decreases as flow rate increases. This behavior is consistent with the decrease of turbulent kinetic energy produced by acoustic streaming in the same 
conditions. In the contrary, thermal enhancement effect produced by acoustic cavitation (25 $\mathrm{kHz}$ ), increases as flow rate increases. This result could be due to the increase of relative size of acoustic bubbles with respect to laminar boundary layer thickness as flow rate increases. In conclusion, the two different ultrasound frequencies, which lead to two different hydrodynamic effects, also lead to two different thermal and turbulence trend with respect to flow rate modifications.

\section{Keywords}

Heat transfer enhancement; ultrasound; forced convection, turbulence

\section{Highlights:}

Hydrodynamic effects of low and high frequency ultrasound within a flow are studied

Thermal enhancement effect produced by both low and high frequency ultrasound is studied

A link is established between thermal and hydrodynamic behaviours with respect to frequency

A phenomenological explanation is proposed for the different behaviors observed

\section{Introduction}

This study compares heat transfer enhancement induced by low and high
frequency.ultrasound. A link is proposed between the observed intensification to the hydrodynamic behavior produced by ultrasound in flowing fluid. Low and high frequency ultrasound are at the origin of hydrodynamic phenomena of different nature. In addition, it is investigated to what extent heat transfer intensification by ultrasound can be linked to the nature of this induced effect. It is therefore expected to give recommendations on the choice 
of ultrasonic frequency in the design of future vibrating heat exchangers depending on parameters such as flow regime, Reynolds number and erosion issues.

\subsection{State of the art}

Ultrasound is a mechanical wave with frequencies above $18-20 \mathrm{kHz}$. Acoustic cavitation and acoustic streaming are two hydrodynamic effects induced by the ultrasonic irradiation of a liquid [1]. Their intrinsic characteristics are strongly dependent on the frequency of the irradiative waves. A schematic description of these both effects is shown in figure 1.

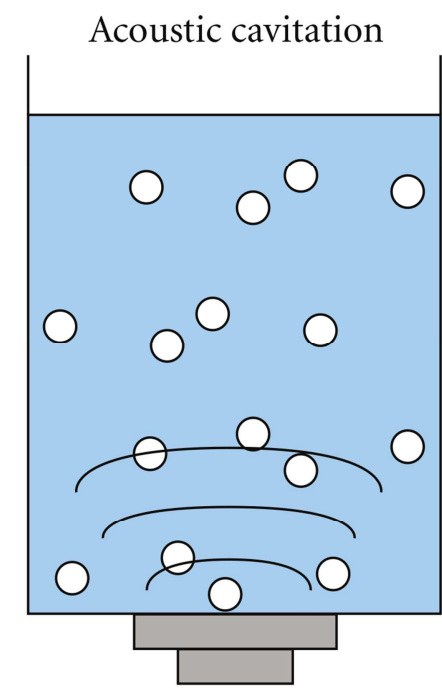

Formation, growth, and collapse of vapor/gas bubbles

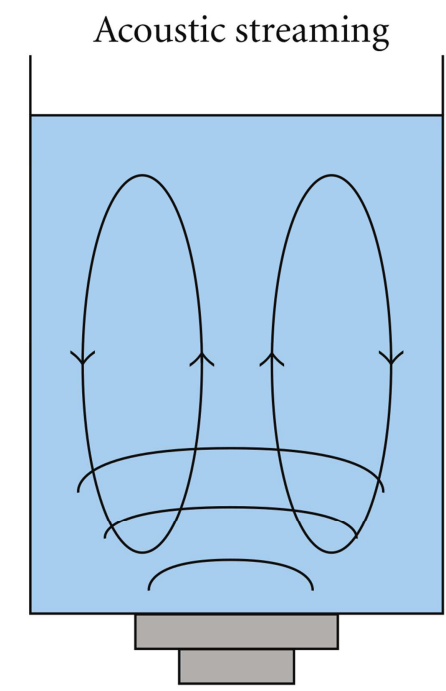

Global fluid flow and possible formation of convection cells

Fig. 1: Illustration of ultrasonic cavitation and acoustic streaming effects as presented in [19]

Acoustic cavitation can be defined as a growing, oscillating and collapsing phenomenon of gas and vapor cavities induced by ultrasound propagation within a liquid. Potential uses of acoustic cavitation for industrial process intensification are wide [1] (heat exchangers, chemical reactors, antifouling/defrosting system...). Nevertheless, strong technological development is still required in terms of reactors design and optimization [2]. Acoustic 
cavitation is able to disturb strongly fluid environment from a hydrodynamic point of view [3] thanks to three different mechanisms:

At first, micro-streaming, induced by the oscillation of the cavitation bubble wall, produces fluid recirculation around it on a distance scale known as acoustic boundary layer. The thickness of this layer relies on both the kinematic viscosity of the medium and the pulsation of the acoustic wave [4]. As an example, in water at $20^{\circ} \mathrm{C}$, acoustic boundary layer ranges from 8 microns with $2 \mathrm{MHz}$ ultrasound to 90 microns with $20 \mathrm{kHz}$ ultrasound [5].

- The second hydrodynamic phenomenon is the acoustic bubbles displacement. Indeed, these latter can be displaced across the fluid by radiation strength because of the absorption and scattering of incident acoustic waves. This is true for both progressive and stationary waves fields. In the second case, the time averaged radiation pressure is equal to zero only at nodes or anti-nodes, driving then bubbles to stable locations [5]. For strong acoustic intensity, void ratio of the liquid increases because of the growing number of bubbles producing an impedance wall which attenuates the acoustic intensity and then the acoustic driven bubbles phenomenon [5-6].

- The third phenomenon is linked to the collapse of the acoustic bubbles which produces strong shock waves within the fluid leading to liquid micro-jets when occurring near a solid wall [5]. In this latter case, collapse leads generally to surface erosion issues, advantageously used in cleaning processes [7-8]. Nevertheless, the erosion phenomenon is an issue to be solved in order to avoid material damage. 
For all these reasons, it has been widely shown that acoustic cavitation is able to trigger or to increase turbulence rate within a liquid flow under laminar or transitional hydrodynamic conditions [9-11].

Acoustic streaming is a generic term defining a liquid or a gas flow driven by acoustic waves. There are two kinds of acoustic streaming depending on conditions at which it is enabled. Thanks to a null net mass flow characteristic, acoustic streaming is able to produce recirculating flows with strong global mixing properties.

- The first one is named Eckart's streaming [12] and appears because of the spatial attenuation of acoustic wave intensity due to liquid absorption, diffraction of the wave leading to energy spreading, or because of the acoustic beam enlargement. In anyway, all these phenomena lead to energy attenuation in the direction of the acoustic wave propagation inducing pressure gradient and then fluid movement. Eckart's streaming usually occurs under propagative wave conditions.

- The second type of acoustic streaming occurs under stationary wave conditions [13]. In this case, the streaming is governed by the dissipation phenomenon occurring within the acoustic boundary layer, i.e. near the oscillating wall of the transducer or near a solid wall exposed to an acoustic wave. Such as for oscillating acoustic bubbles, this leads to recirculating flows within the acoustic boundary layer giving rise to others recirculation modes into the bulk by propagating the movement from one cell to the next one. Near the walls, mixing effects combined with strong shearing strength, are able to lyse cells walls [14].

Both types of streaming are able to induce turbulent flows [15-16]. Mixing properties of ultrasound were evidenced within sonochemical reactors by Residence Time Distribution (RTD) measurements [17-18]. According to the literature, acoustic streaming observed at 
$500 \mathrm{kHz}$ ultrasound results in strong stirring effects leading to RTD results classically observed with mechanically full-stirred reactors [17].

The main effect limiting the convective heat transfer is the presence of a laminar boundary layer (also called viscous sub-layer) near the wall. This is usually defined as a flow region where the thermal diffusion is predominant, contrary to thermal convective effects that prevail in the bulk. A decrease of its thickness allows to reduce the thermal resistance of this interface and thereby to increase heat transfer rate. Stirring, mixing and turbulence properties of both acoustic cavitation and acoustic streaming render consequently ultrasound as an attractive and active method to enhance heat transfer. By this way, heat transfer intensification could also help to achieve two main objectives:

- thermal transfer increase between two fluids separated by a solid interface with fixed parameters (case of heat exchangers)

- temperature difference decrease keeping the same heat flux when sensitive fluids are processed (case of liquid food pasteurization)

Studies on heat transfer enhancement by ultrasound began in the middle of the $20^{\text {th }}$ century. It can be noticed that most of these studies are focused on phase change, like boiling [20-21], or on natural convection [22]. Some studies dealt also with heat transfer in forced convection or in the field of heat exchangers but in a less extend. Most of the recent studies have for main purpose fouling reduction [23]. However, some works since 2000 are devoted to heat transfer enhancement in forced convection by using ultrasound:

- $\quad$ Most of them use low frequency ultrasound (20 kHz to $100 \mathrm{kHz}[19,24-25])$. Intensification of heat transfer up to $270 \%$ has been reported using a $35 \mathrm{kHz}$ vibrating shell and tube heat exchanger [26]. 
- High frequency effect of ultrasound on heat transfer has also been highlighted through recent works showing how acoustically induced streaming can enhance convective heat transfer coefficients [27].

- Studies on cooling process have also been successfully performed [28-30] leading to a $27 \%$ heat transfer enhancement.

One might here consider that a positive effect on heat transfer has always been reported in all studies involving ultrasound. A comprehensive overview can be found in two publications $[24,31]$. However, it appears that most of the studies deal with heat transfer enhancement by using ultrasound in a very general way. Only a few of them have been carried out in a phenomenological way especially with the impact of ultrasound on the boundary layer or on the turbulence rate within the liquid flow $[3,7,9,27,32]$.

According to the literature, it is reasonable to identify four main parameters that clearly influence heat transfer enhancement by ultrasound. Whereas two of them do concern geometry configuration and fluid properties, the two others relate to ultrasonic wave characteristics:

- Geometry of the system: the distance between the exchange surface and the ultrasonic transducer is an important parameter to be taken into account as it acts directly on acoustic intensity especially in the presence of cavitation [33-34]. Moreover, the angle of radiation has a significant impact on thermal results for natural convection in the presence of acoustic cavitation [35].

- Fluid used may have different physicochemical properties affecting ultrasonic effects previously described. For example, bubble behavior is driven by saturation pressure and surface tension [5]. Viscous fluids are less sensitive to cavitation [5]. On the other hand, increasing the fluid viscosity (bulk and dynamic) leads to an 

prime importance into acoustic forces induced by a plane acoustic wave responsible for acoustic streaming phenomenon [36]. on enhancement values $[24,30,37]$.

Modeling of thermo-hydraulic effects generated by ultrasound is of prime importance for the integration of this technology to optimize many industrial processes using heat exchangers.

As aforesaid, very few articles deal with enhancement of heat transfer in forced convection using ultrasound. Main experimental set-ups use shell and tube heat exchanger geometry and low ultrasound frequency $(20 \mathrm{kHz}$ to $100 \mathrm{kHz}$ ). Furthermore, most of them were limited to cavitation effect on heat transfer intensification and reported the influence of liquid flow rate

Some mathematical [38] and numerical [39-41] models dealing with hydrodynamic effects of ultrasound have been released. These models have been designed for low [39-41] and high [38] frequency range and specific conditions of use of ultrasound. It is therefore necessary to investigate, identify and qualify parameters involved on thermo-hydraulic effects induced by ultrasound in a larger way in order to feed these models. Over all, it is still 
174 phenomenologically unclear how ultrasonically induced phenomena (cavitation and 175 streaming) can modify a flow.

\subsection{Objectives}

The objectives of this work are thus to carry out both hydrodynamic and thermal approaches in the presence of intense acoustic cavitation $(25 \mathrm{kHz})$ or strong acoustic streaming $(2 \mathrm{MHz})$ in order to propose a relevant phenomenological explanation of the frequency effect. Motivation for using high frequency ultrasound comes from strong erosion issues that could occur in heat exchangers by using low frequency ultrasound even if antifouling action at this frequency has been proved [42]. In the aim of designing future optimized vibrating heat exchangers, it is highly desired to compare thermal performances in relation with phenomena implied at low and high frequency ultrasound. Benefits and drawbacks for both frequencies with respect to specific requirements and operating conditions of these future heat exchangers will then be analyzed.

\section{Experimental apparatus and data reduction}

\subsection{General presentation of the test section}

An experimental setup was designed and built (Fig. 2) in order to investigate heat transfer intensification in forced convection by ultrasound. An overall description of the bench test used for this study has been detailed in a previous article in which preliminary results of heat transfer enhancement using $2 \mathrm{MHz}$ ultrasound were exposed [27]. 


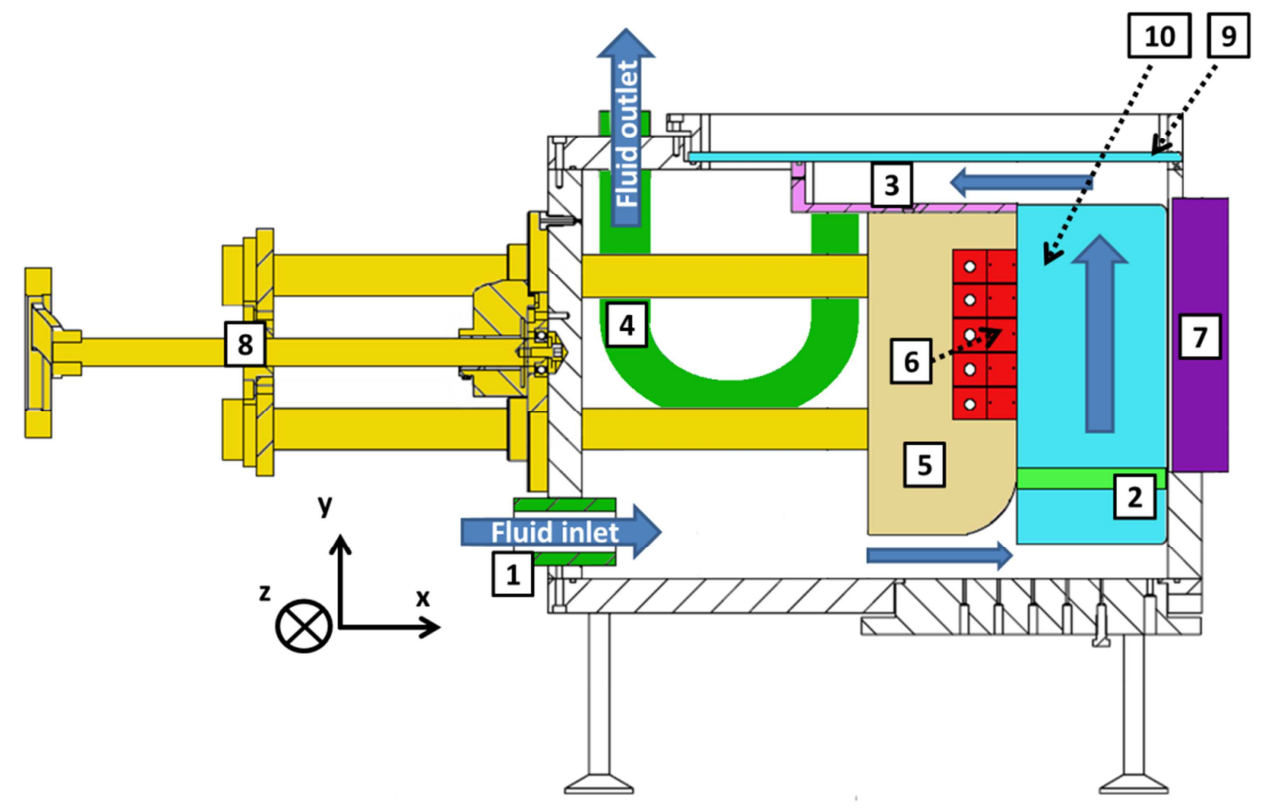

Fig. 2: Side view of the test section ALTO used for this study.

The fluid enters into the test section in $\mathbf{1}$ and follows blue arrows on Fig. 2. It passes then through a porous media $\mathbf{2}$ in order to ensure a flat velocity profile. The fluid flows throughout a rectangular canal and is then collected at the top of this canal in $\mathbf{3}$. It exits the test section by

a pipe in 4 . The canal is made of a block composed of an insulating material that encompass five heating plate blocks (respectively 5 and 6) and by the ultrasonic transducer (7). The heating plate (6) is made of five stacked heating elements, thermally insulated from each other and individually power supplied [27]. Each element is equipped with temperature sensors in order to determine local convective heat transfer coefficients. The thickness of the canal (xaxis) can be changed by using the device 8 . In this present study, the canal size is $30 * 100 \mathrm{~mm}(\mathrm{x}-\mathrm{z}$ plan) and the total heat plate (6) length is $100 \mathrm{~mm}$ (y axis). Finally, two perpendicular visualization windows (9 and 10) allow measuring velocity and turbulent fields in the $\mathrm{x}-\mathrm{y}$ plan thanks to a 2D-2C Particle Image Velocimetry (PIV) method.

Local heat transfer coefficients in front of each heating element can be determined following the procedure described in [27]. It is thereby possible to calculate Nusselt number as follows: 
$N u=\frac{h_{i} d_{h}}{\lambda}$

208 with $h_{i}\left[\mathrm{~W} / \mathrm{m}^{2} / \mathrm{K}\right]$ the local convective heat transfer coefficient in front of the $\mathrm{i}^{\text {th }}$ heating

209 element, $d_{h}[\mathrm{~m}]$ the hydraulic diameter and $\lambda[\mathrm{W} / \mathrm{m} / \mathrm{K}]$ the thermal conductivity of the fluid.

210 Heat Transfer Enhancement Factor $(H T E F)$ can then be defined as:

211

$H T E F=\frac{N u_{u s}-N u_{\text {silent }}}{N u_{\text {silent }}}$

213 where $N u_{u s}$ and $N u_{\text {silent }}[-]$ are the Nusselt numbers with and without ultrasound 214 respectively.

\subsection{Characterization of ultrasound transducers}

216 In this work, two different ultrasonic frequencies were used. in order to compare specific

217 effects of acoustic streaming and of acoustic cavitation on convective heat transfer in forced

218 convection. To ensure comparison, the ultrasonic power delivered to the liquid flowing

219 throughout the canal was estimated by means of a classical calorimetric method and kept

220 identical for both transducers. The $25 \mathrm{kHz}$ transducer was specifically designed by Sinaptec

221 with an active surface size identical to that of the $2 \mathrm{MHz}$ Sonosys transducer. Both

transducers were purposely characterized in order to evaluate the presence or not of acoustic

cavitation and of acoustic streaming using $25 \mathrm{kHz}$ or $2 \mathrm{MHz}$. It was confirmed that $2 \mathrm{MHz}$

ultrasound irradiation mainly results in strong acoustic streaming. Acoustic cavitation was not

revealed by chemical (iodide oxidation) and aluminum foil tests for this frequency ( $2 \mathrm{MHz}$ ).

On the other hand, none significant chemical activity was observed using iodide oxidation test 
According to these results, it was assumed that the low-frequency transducer $(25 \mathrm{kHz})$ only

230 produces acoustic cavitation with strong mechanical effects whereas the high frequency one

(2 $\mathrm{MHz}$ ) only induces acoustic streaming. The great difference in the nature of the

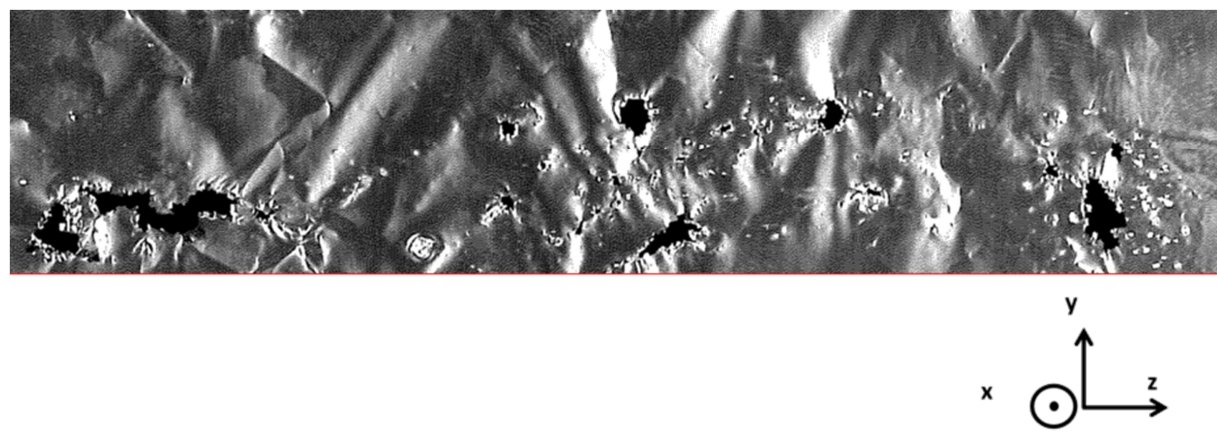

Fig. 3: Erosion pit clustering (black part) of the aluminum foil covering the entire $5^{\text {th }}$ heating element facing the $25 \mathrm{kHz}$ transducer. Total ultrasonic power $=110 \mathrm{~W}$, distance from the transducer $=30 \mathrm{~mm}$, exposure time $=60$ seconds.

\subsection{Particle Image Velocimetry (PIV) set-up}

Hydrodynamic modifications in the flow induced by ultrasound were investigated by PIV technique using the set-up described in [27]. The laser is a Nd-Yag (Litron provided by

Dantec Dynamics) with two cavities generating $200 \mathrm{~mJ}$ of maximum energy for 6-9 ns pulse time. The camera is an ImagerProX2 M (provided by LaVision) with a $1600 * 1200$ pixels spatial resolution. Each of the pixels of the camera measures $7.4 * 7.4 \mu \mathrm{m}^{2}$. Average fields are obtained from 2000 instantaneous fields.

243 The measurement field size is equal to the size of the canal in front of the $\mathrm{i}^{\text {th }}$ heating block 244 (30 mm thick by $20 \mathrm{~mm}$ high on $\mathrm{x}-\mathrm{y}$ plan). The camera lens is a Nikon $150 \mathrm{~mm}$, leading to 
PIV field pixels equals to $16.5 * 16.5 \mu \mathrm{m}^{2}$. Interrogation windows are $16 * 16$ pixels leading to a square of $0.264 * 0.264 \mathrm{~mm}^{2}$. Consequently, PIV measurement provides measurement fields of the entire canal thickness (x-axis) on the entire $\mathrm{i}^{\text {th }}$ heating block height (y-axis). These PIV measurements allow us to link thermal phenomenon to hydrodynamic ones that

PIV device gives instantaneous velocity fields from which it is possible to calculate average velocity fields from 2000 instantaneous velocity fields. RMS velocity [m/s] fields and turbulent kinetic energy $(T K E)\left[\mathrm{m}^{2} / \mathrm{s}^{2}\right]$ on the two dimensions $\mathrm{x}-\mathrm{y}$ plan for the 2000 instantaneous velocity fields can then be calculated thanks to the following equation:

$T K E=\frac{3}{4} V_{R M S}^{2}$

with $V_{R M S}[\mathrm{~m} / \mathrm{s}]$ the root mean square velocity as calculated by the following equation:

$V_{R M S}=\sqrt{\frac{\sum_{\mathrm{i}=1}^{\mathrm{N}}\left(\mathrm{V}_{\mathrm{i}}-\overline{\mathrm{V}}\right)^{2}}{(\mathrm{~N}-1)}}$

where $V_{i}[\mathrm{~m} / \mathrm{s}]$ is the value of the modulus of the instantaneous velocity of the $i^{\text {th }}$ image on a total of 2000 images and $\overline{\mathrm{V}}[\mathrm{m} / \mathrm{s}]$ is the modulus of the average velocity. It is assumed that the velocity component $V_{z}$, which is not measured because of the $x-y$ plan orientation of the laser sheet, contains a similar contribution as the one contained within the values of $V_{x}$ and $V_{y}$ [43]. This assumption implies isotropy of the turbulence even if it is questionable near the heating 261 plate. Nevertheless, the correction of $3 / 4$ instead of $1 / 2$, classically used for turbulence 262 calculated from planar velocity fields, does not change the observed phenomenology. It only affects the absolute values. Since this study is mainly phenomenological and aims at 
comparing the effects at two different ultrasonic frequencies, the bias will therefore be

265 identical for all measurements without being detrimental to the analysis.

\subsection{Operating parameters and experimental protocol}

Operating hydrodynamic parameters used in this study are displayed in Tab.1. Flowrates range from 215 up to $1315 \mathrm{~L} / \mathrm{h}$ with respect to technical abilities of the test bench resulting in Reynolds numbers from 900 (laminar) to 5500 (transitional/turbulent). Properties of the water are those at the inlet temperature $\left(20^{\circ} \mathrm{C}\right)$.

\begin{tabular}{|l|l|l|l|l|l|l|}
\hline Flowrate [L/h] & 215 & 358 & 600 & 835 & 1074 & 1315 \\
\hline Reynolds number & 900 & 1500 & 2500 & 3500 & 4500 & 5500 \\
\hline Flow Velocity [m/s] & 0.020 & 0.033 & 0.056 & 0.077 & 0.099 & 0.122 \\
\hline
\end{tabular}

Tab. 1 : Operating parameters

271 Canal thickness (x-axis) was kept constant at $30 \mathrm{~mm}$ in this study whereas canal width (z-

272 axis) and canal height (y-axis) were both set at $100 \mathrm{~mm}$. Thermal measurements reported in

273 this paper were done in front of the fifth heating block, i.e. the upper block of the heating

274 plate, which is $20 \mathrm{~mm}$ height (see Fig. 1). This choice was made because of the fully

275 developed hydrodynamic and thermal conditions in front of the fifth block as previously 276 shown [27]. The hydraulic diameter is equal to $0.046 \mathrm{~m}$ for this series of measurements. To

277 ensure a fair comparison, the ultrasonic power was kept constant to $110 \mathrm{~W}$ for both $25 \mathrm{kHz}$ 278 and $2 \mathrm{MHz}$ with the assumption of uniform distribution of $22 \mathrm{~W}$ per heating element.

279 Moreover, the total heating power being equal to $450 \mathrm{~W}$, each heating element is assumed to 280 deliver uniformly $90 \mathrm{~W}$.

\section{Results and discussions}




\subsection{Thermal results for $25 \mathrm{kHz}$ and $2 \mathrm{MHz}$ sonication}

283 Thermal results obtained in silent conditions and for both ultrasound configurations $(25 \mathrm{kHz}$

284 and $2 \mathrm{MHz}$ ) are plotted on Fig. 4. Nusselt numbers are given with respect to the fluid flow

285 velocity and corresponding Reynolds number (constant canal thickness). Experimental results

286 clearly demonstrate the thermal enhancement induced by ultrasound when Nusselt numbers

287 are compared to those of silent regime, whatever the incident irradiative frequency. On silent

288 mode, the evolution of the Nusselt number is consistent with the fact that the heat transfer

289 coefficient increases when the liquid flow rate increases and thereby corresponding flow

290 velocity. These results confirm classical results in forced convection for silent regime, i.e.

291 Nusselt increases as Reynolds increases. This can be fully explained by the decrease of the

292 laminar boundary layer thickness near the heating wall leading thereby to the decrease of the

293 corresponding thermal resistance [44]. However, it is important to note that the

294 laminar/turbulent transition classically observed for Reynolds numbers between 2000 and

2953000 in internal forced convection is not experimentally observed here. This can be explained

296 by the presence of a $90^{\circ}$ turn at the fluid inlet. This unusual configuration seems to generate

297 hydrodynamic disturbances, causing a gradual enhancement of heat transfer for Reynolds

298 numbers lower than 2000. This behavior is contrary to theory, which predicts constant Nusselt

299 in laminar regime. 


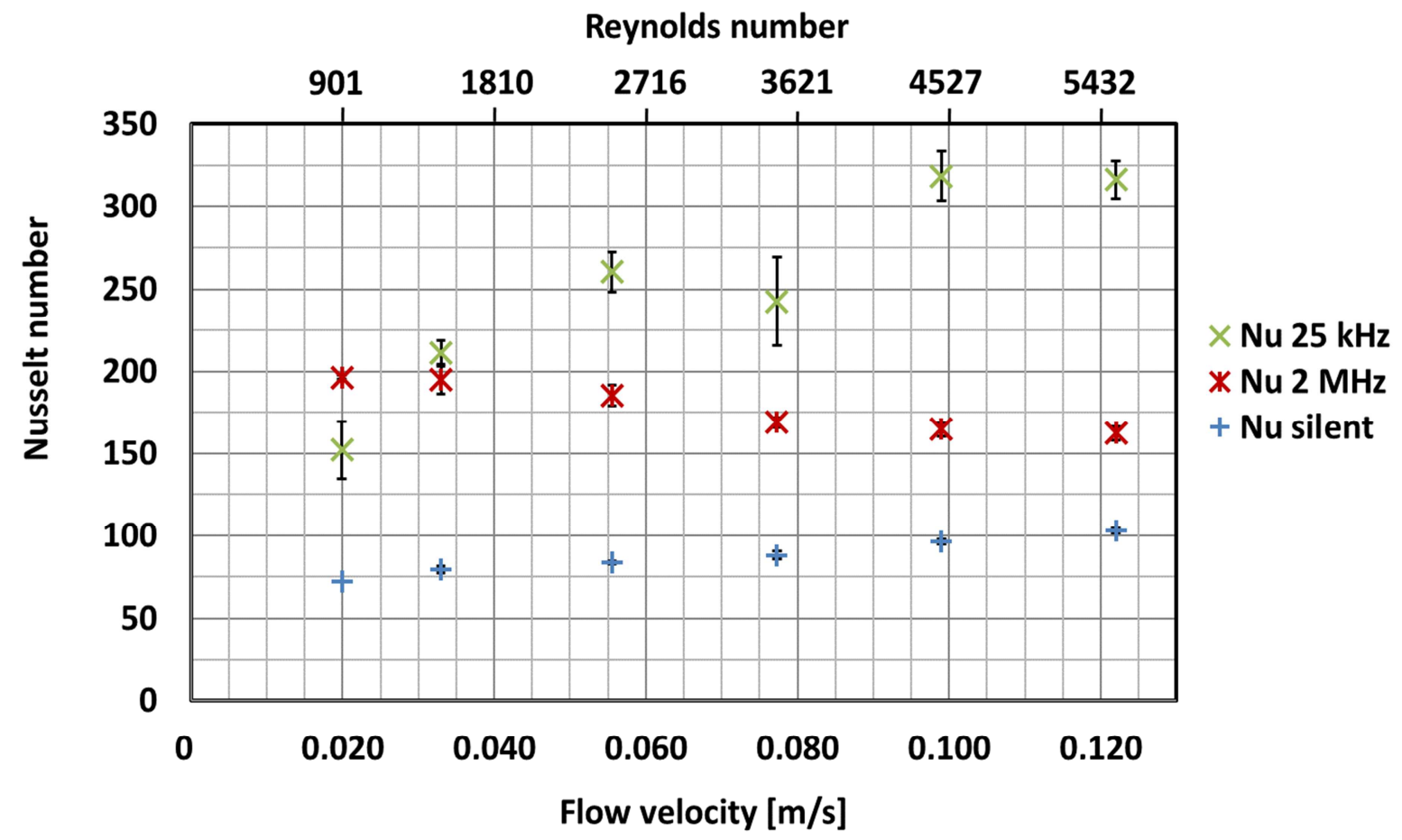

Fig. 4: Nusselt number vs mean flow velocity and Reynolds number for silent conditions, $25 \mathrm{kHz}$ and $2 \mathrm{MHz}$ ultrasound. Heating element $\mathrm{n}^{\circ} 5$, total ultrasound power $110 \mathrm{~W}$, total heating power $450 \mathrm{~W}$. The uncertainty bars are drawn in black for all points on the graph.

As stated before, the presence of an ultrasonic field enhances heat transfer but more interestingly, these results highlight its dependency towards the ultrasonic frequency. Indeed, at high frequency $(2 \mathrm{MHz})$, an increase of the flow velocity leads to a slow decrease of the observed heat transfer intensification. The reverse occurs at $25 \mathrm{kHz}$ where an increase of flow velocity leads to an increase of the Nusselt number reaching a plateau for the highest tried flow velocities and Reynolds numbers. Surprisingly, at the lowest investigated flow velocity in this study, the intensification of heat transfer is stronger at $2 \mathrm{MHz}$ than at $25 \mathrm{kHz}$; whereas beyond flow velocities of $0.033 \mathrm{~m} / \mathrm{s}$ (i.e. $\mathrm{Re}=1500$ ) heat transfer enhancement is higher using low frequency ultrasound. In order to understand and to propose relevant explanations for the difference highlighted by thermal results despite the same supplied ultrasonic and thermal power, a hydrodynamic study using PIV was then performed. 


\subsection{Hydrodynamic study results under $25 \mathrm{kHz}$ and $2 \mathrm{MHz}$ sonication}

312

313

314

315

316

\subsubsection{Preliminary observations without ultrasound}

The average velocity field observed without ultrasound is given in Fig. 5 for mean flow velocities of $0.020 \mathrm{~m} / \mathrm{s}$ (a) and $0.122 \mathrm{~m} / \mathrm{s}$ (b) corresponding to Reynolds numbers of 900 (a) and 5500 (b). As expected, the found pattern illustrates a fluid flowing classically within a rectangular canal from bottom to top along y-axis direction. As clearly shown, there is none velocity component along $\mathrm{x}$-axis. Although these results were expected, it was useful to validate them experimentally before comparison with flow patterns recorded under ultrasound at $25 \mathrm{kHz}$ or $2 \mathrm{MHz}$.


Fig. 5: Average velocity fields observed under silent conditions, heating block $\mathrm{n}^{\circ} 5$, canal 
thickness $30 \mathrm{~mm}$, hydraulic diameter $=0.046 \mathrm{~m}$. Mean flow velocity $=0.020$ (a) and 0.122 (b) $\mathrm{m} / \mathrm{s}$ corresponding to Reynolds number $=900$ (a) and 5500 (b), Vectors give flow direction and color scale gives velocity values.

\subsubsection{Experimental results in the presence of $2 \mathrm{MHz}$ ultrasound}

For a mean flow velocity equal to $0.020 \mathrm{~m} / \mathrm{s}$ (i.e. Reynolds $=900$ ), the flow pattern is strongly

disturbed by sonication at $2 \mathrm{MHz}$, resulting in local velocity value increase and flow direction modifications as clearly shown in Fig. 6.a. The canal filled with water induces a resonating cavity for $2 \mathrm{MHz}$ ultrasound waves equal to 40 wavelengths. This number is verified experimentally and corresponds to the number of ridges visible on Fig 6.a. Higher velocity values (around $0.240 \mathrm{~m} / \mathrm{s}$ ) can be also spotted out in the vicinity of the heating wall. The Schlichting streaming, classically occurring around vibrating walls or solid walls submitted to stationary waves, is probably at the origin of this phenomenon. Velocity value increases also into the bulk to reach $0.160 \mathrm{~m} / \mathrm{s}$. For a higher mean flow velocity $(0.122 \mathrm{~m} / \mathrm{s}$, Reynolds $=$ 5500), changes in the flow pattern are not so marked as shown in Fig. 6 b. Some weak flow direction modifications are still visible, but the $2 \mathrm{MHz}$ velocity field (Fig 6.b) is very close to the one measured in silent conditions (Fig 5.b). Hydrodynamic effects due to the secondary flow produced by $2 \mathrm{MHz}$ ultrasound on the $\mathrm{x}$-axis direction are strongly affected by the mean flow velocity. It is demonstrated here that modifications of flow pattern, due to the presence 

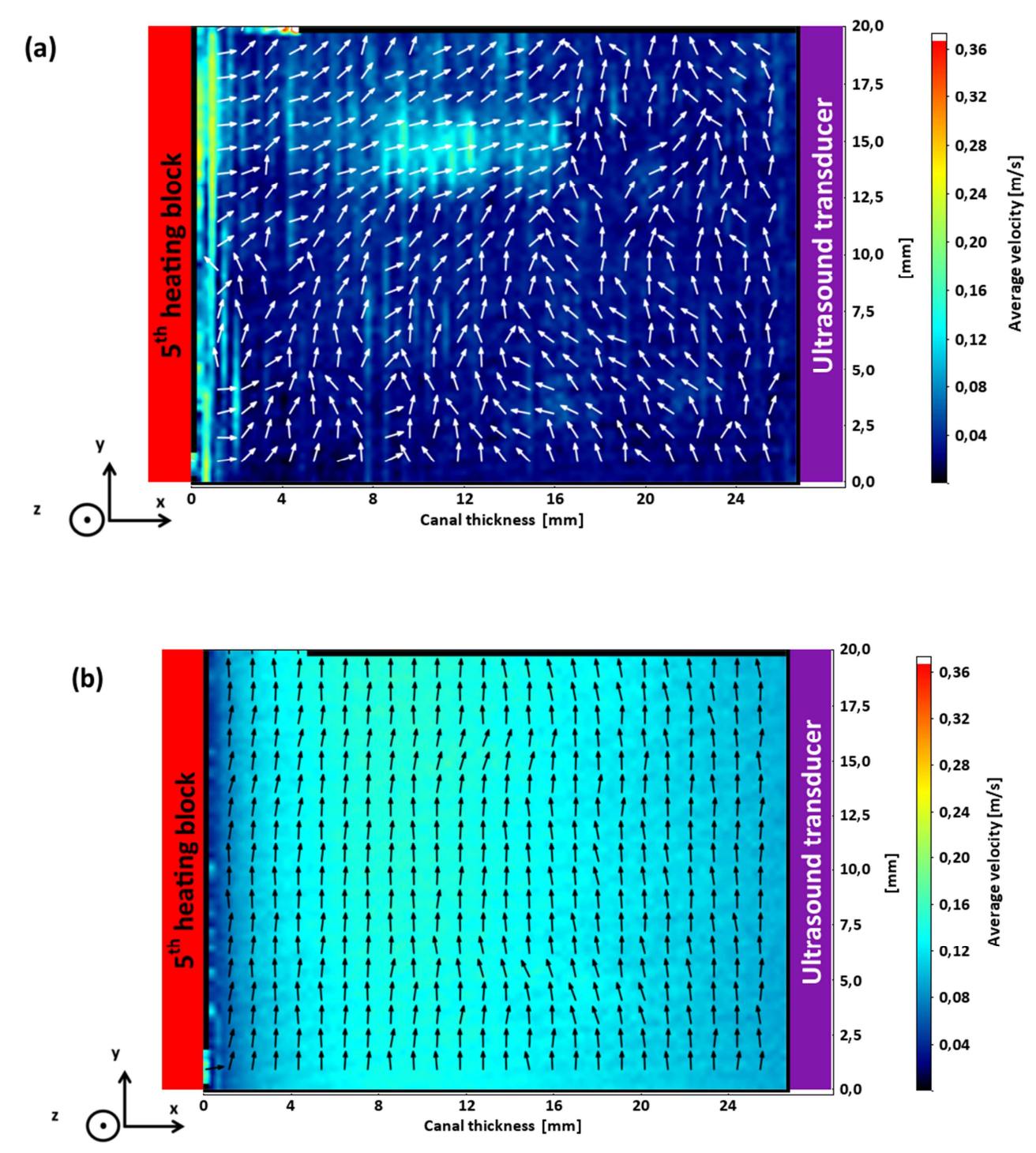

Fig. 6: Average velocity field observed with $2 \mathrm{MHz}$ irradiation, heating block $\mathrm{n}^{\circ} 5$, canal thickness $30 \mathrm{~mm}$, hydraulic diameter $=0.046 \mathrm{~m}$. Mean flow velocity $=0.020$ (a) and 0.122 (b) m/s corresponding to Reynolds = 900 (a) and 5500 (b), Vectors give flow direction and color scale gives velocity values.

337 As mentioned in the state of the art, the relationship between acoustic streaming and induced 338 turbulences within a liquid or a flow has been already established [16]. The hydrodynamic 339 behavior analysis of the average velocity fields presented in Fig. 6 can thus explain those 340 presented in Fig. 7 wherein turbulent kinetic energy fields are reported. Turbulent kinetic 341 energy (TKE) field with a mean flow velocity of $0.020 \mathrm{~m} \cdot \mathrm{s}^{-1}(\operatorname{Re}=900)$ reveals that positions 
of TKE highest values $(12.5 \mathrm{~mm}<\mathrm{y}<20 \mathrm{~mm})$ do correspond to the ones where the average

343 velocity field is the most disturbed. Attenuation of velocity field modification by $2 \mathrm{MHz}$

344 ultrasound, with respect to the mean flow velocity increase (and corresponding Reynolds

345 number) illustrated in Fig.6, can be directly correlated to the decrease of the TKE values in

346 the same experimental conditions as reported in Fig.7. Similarly, the decrease of Turbulent

347 Kinetic Energy produced by $2 \mathrm{MHz}$ ultrasound with respect to the mean flow velocity

348 increase can be linked to the decrease of Nusselt number as detailed in Fig. 4 under the same

349 conditions.

350 The present study is not able to determine real causes of this extinguishing phenomenon of the

351 streaming strength when liquid flowrate is increased. Nevertheless, two hypotheses can be

352 drawn at this point. At first, the flow observed within the canal for $2 \mathrm{MHz}$ sonication may be

353 produced by the combination of the pumping pressure due to the mean flow on the y-axis

354 direction and radiation pressure due to the secondary flow on the $\mathrm{x}$-axis direction (acoustic

355 streaming). Consequently, the higher the pumping pressure in comparison with the radiation

356 pressure (which is constant because of ultrasound power kept constant in this study), the

357 lesser the influence of acoustic streaming is. The second hypothesis could be that the pressure

358 field within the canal is disturbed when the flow becomes more turbulent because of pressure

359 fluctuations induced by turbulences leading possibly to a masking effect, thus hindering

360 acoustic wave propagation and then acoustic streaming production. A future Reynolds

361 similarity study could be helpful to answer to this question. 
Flow velocity $0.020 \mathrm{~m} / \mathrm{s}$

(Re 900)

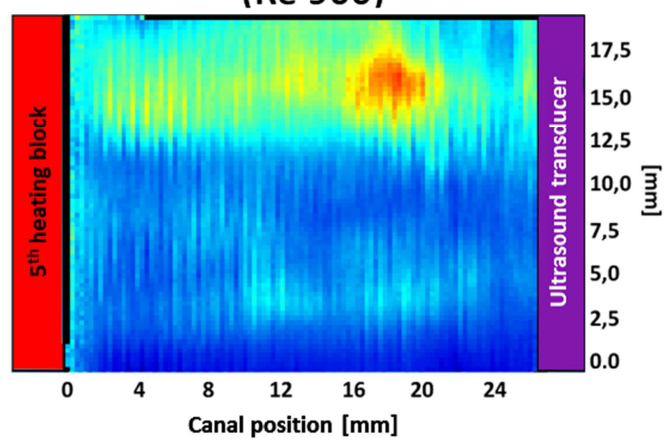

Flow velocity $0.056 \mathrm{~m} / \mathrm{s}$

(Re 2500)

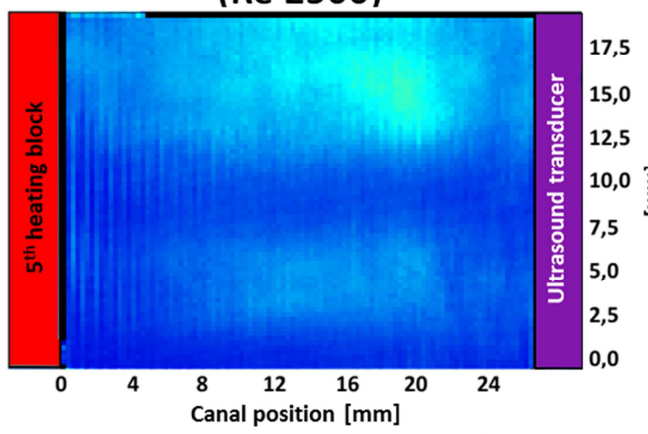

Flow velocity $0.099 \mathrm{~m} / \mathrm{s}$

$(\operatorname{Re} 4500)$

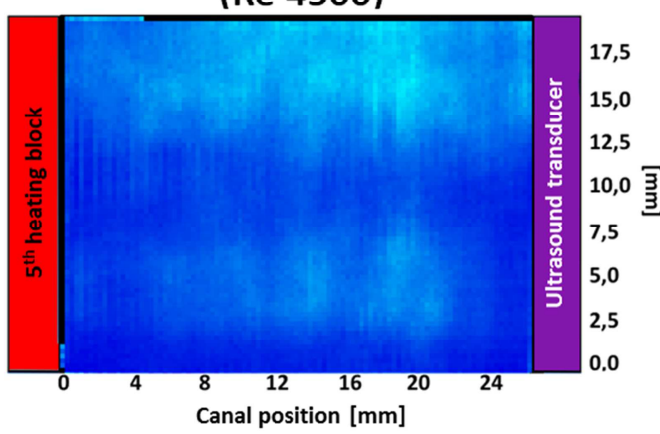

Flow velocity $0.033 \mathrm{~m} / \mathrm{s}$

(Re 1500)

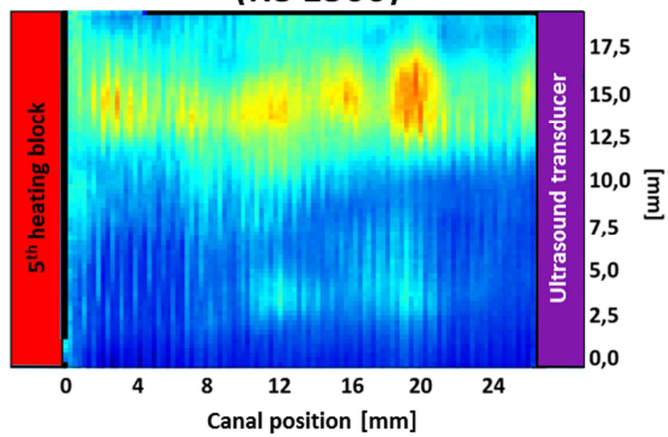

Flow velocity $0.077 \mathrm{~m} / \mathrm{s}$

$(\operatorname{Re} 3500)$

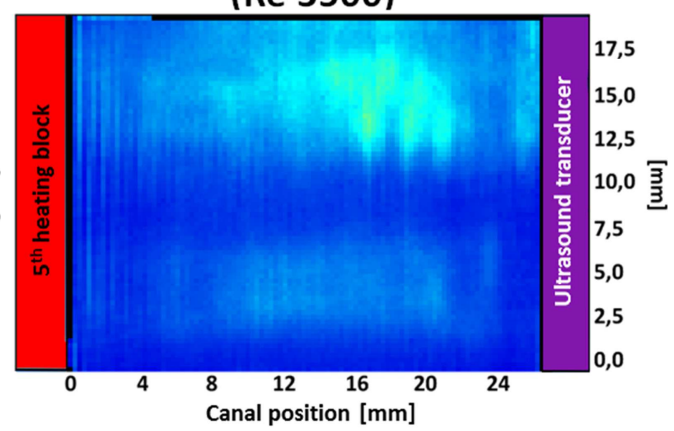

Flow velocity $0.122 \mathrm{~m} / \mathrm{s}$

(Re 5500)

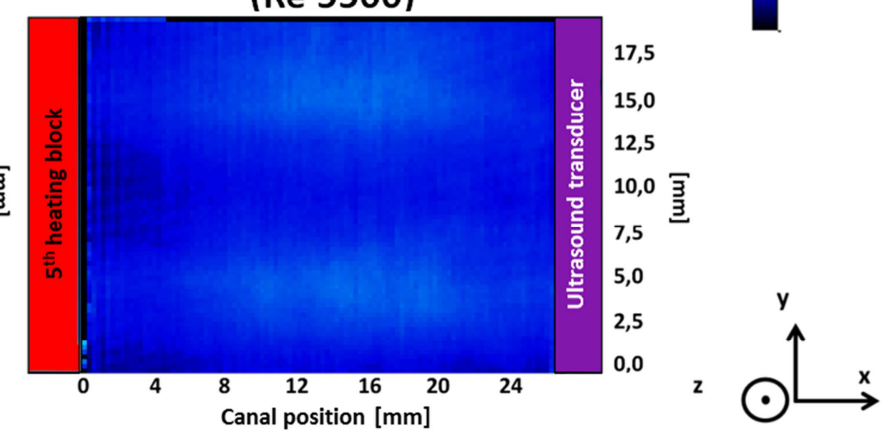

Fig. 7: Turbulent kinetic energy fields estimated in front of the $5^{\text {th }}$ heating block for 6 mean flow velocities. Ultrasound frequency $=2 \mathrm{MHz}$, canal thickness $=30 \mathrm{~mm}$, hydraulic diameter $=0.046 \mathrm{~m}$, total ultrasound power $=110 \mathrm{~W}$.

\subsubsection{Experimental results in the presence of $25 \mathrm{kHz}$ ultrasound}

363 Average velocity fields for $25 \mathrm{kHz}$ sonication are displayed in Fig. 8. Their comparison with

364 those of the Fig. 5 (silent regime) highlights that direction and values of the velocity are quite

365 similar in both ultrasonic and silent modes. Few vectors deviations are visible only nearby the 

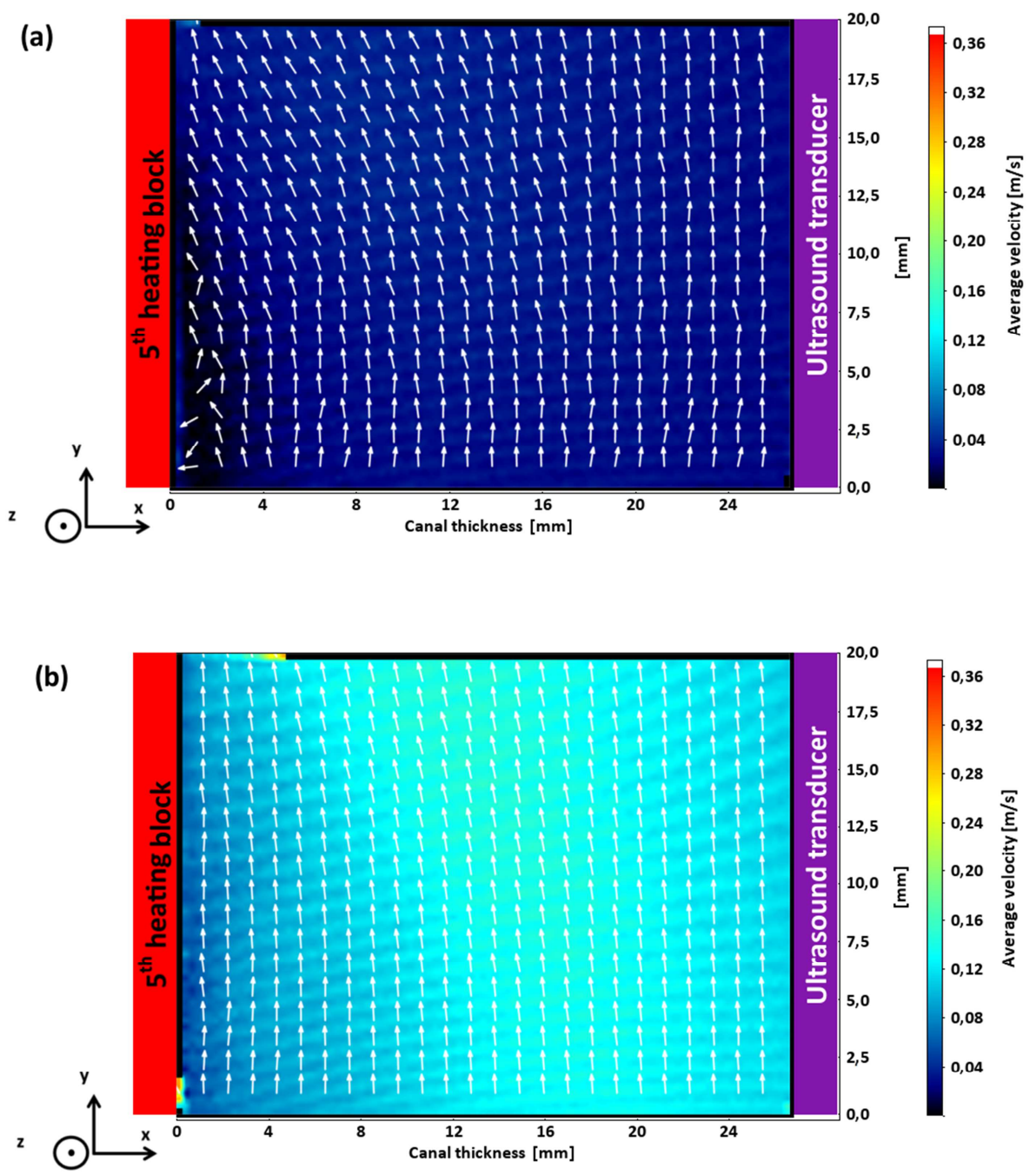

Fig. 8: Average velocity fields observed with $25 \mathrm{kHz}$ ultrasound sonication, mean flow velocity $=0.020$ (a) and $0.122(\mathrm{~b}) \mathrm{m} / \mathrm{s}$ corresponding to Reynolds $=900$ (a) and 5500 (b), hydraulic diameter $=0.046 \mathrm{~m}$. Vectors give flow direction and color scale gives velocity values.

Fig. 9 compares instantaneous velocity fields under both silent (a) and $25 \mathrm{kHz}$ (b) regimes for a Reynolds number equal to 900 . Ultrasonic cavitation is a temporal stochastic but spatially homogeneous distributed phenomenon as shown on Fig. 9 (b) for the lowest mean flow 

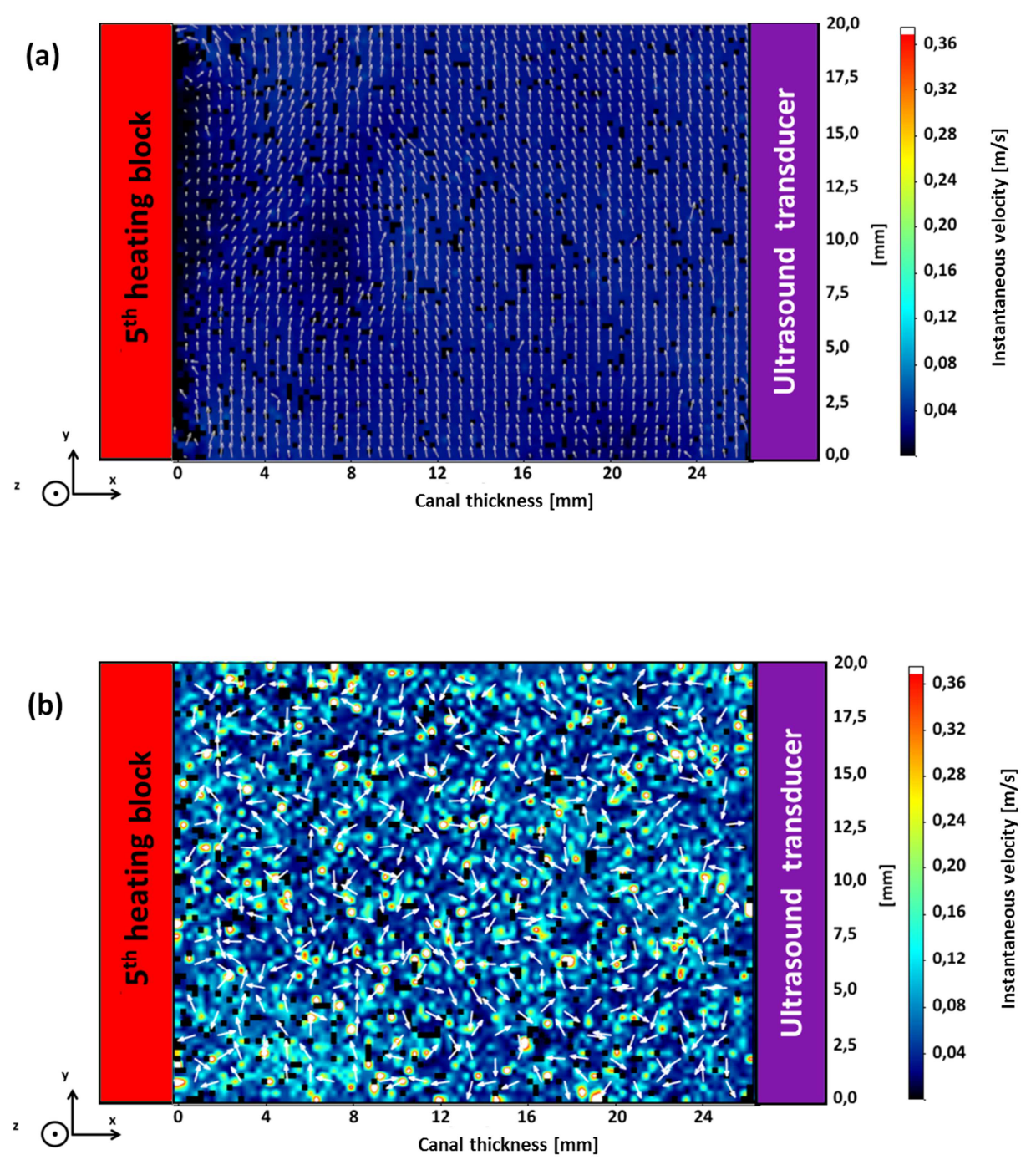

Fig. 9: Instantaneous velocity fields observed under silent regime (a) and under $25 \mathrm{kHz}$ sonication (b). Mean flow velocity $=0.020 \mathrm{~m} / \mathrm{s}$ corresponding Reynolds $=900$, hydraulic diameter $=0.046 \mathrm{~m}$. Vectors give instantaneous velocity directions and color scale gives velocity values.

373 Both acoustic bubble oscillations and collapses probably induce jointly these high velocity 374 spots within the fluid as illustrated in Fig. 10. This figure shows one of the 2000 PIV doublet 375 image zoomed on a collapsing cluster bubble (high color level pixels on images (a) and (b)) 
recorded by the camera for a mean flow velocity of $0.020 \mathrm{~m} / \mathrm{s}$. The collapse induces a

377 reduction of the area occupied by bubbles as shown with added double doted arrows on 378 images (a) and (b) of Fig. 10. This PIV doublet subsequently gives the instantaneous velocity 379 field (image (c)). The maximum velocity induced by the cluster collapse reach $0.100 \mathrm{~m} / \mathrm{s}$. Its 380 position corresponds to one of the collapsing cluster areas. Consequently, bubbles strongly 381 disturb the flow velocity within a disturbance area, which is of bigger size than the cluster 382 bubble itself (black doted arrow on image (c) of Fig. 10). Two hypotheses can be drawn to explain this phenomenon. In the one hand, the violent bubble wall move induces fluid entrainment away from it. This may be supported by the fact that interrogation windows all around the cluster area display also higher velocity values than $0.020 \mathrm{~m} / \mathrm{s}$, which is the mean flow velocity. The second hypothesis is a bias of the velocity calculation. Indeed, the velocity 387 is calculated on a $16 * 16$ pixel interrogation window whose each pixel measures $38816.5 * 16.5 \mu \mathrm{m}^{2}$. Consequently, PIV measurements are not able to clearly distinguish 389 phenomena inducing effects within an area smaller than $264 * 264 \mu \mathrm{m}^{2}$. In this study, the used 390 interrogation window size gives the most accurate measurement technically possible. 


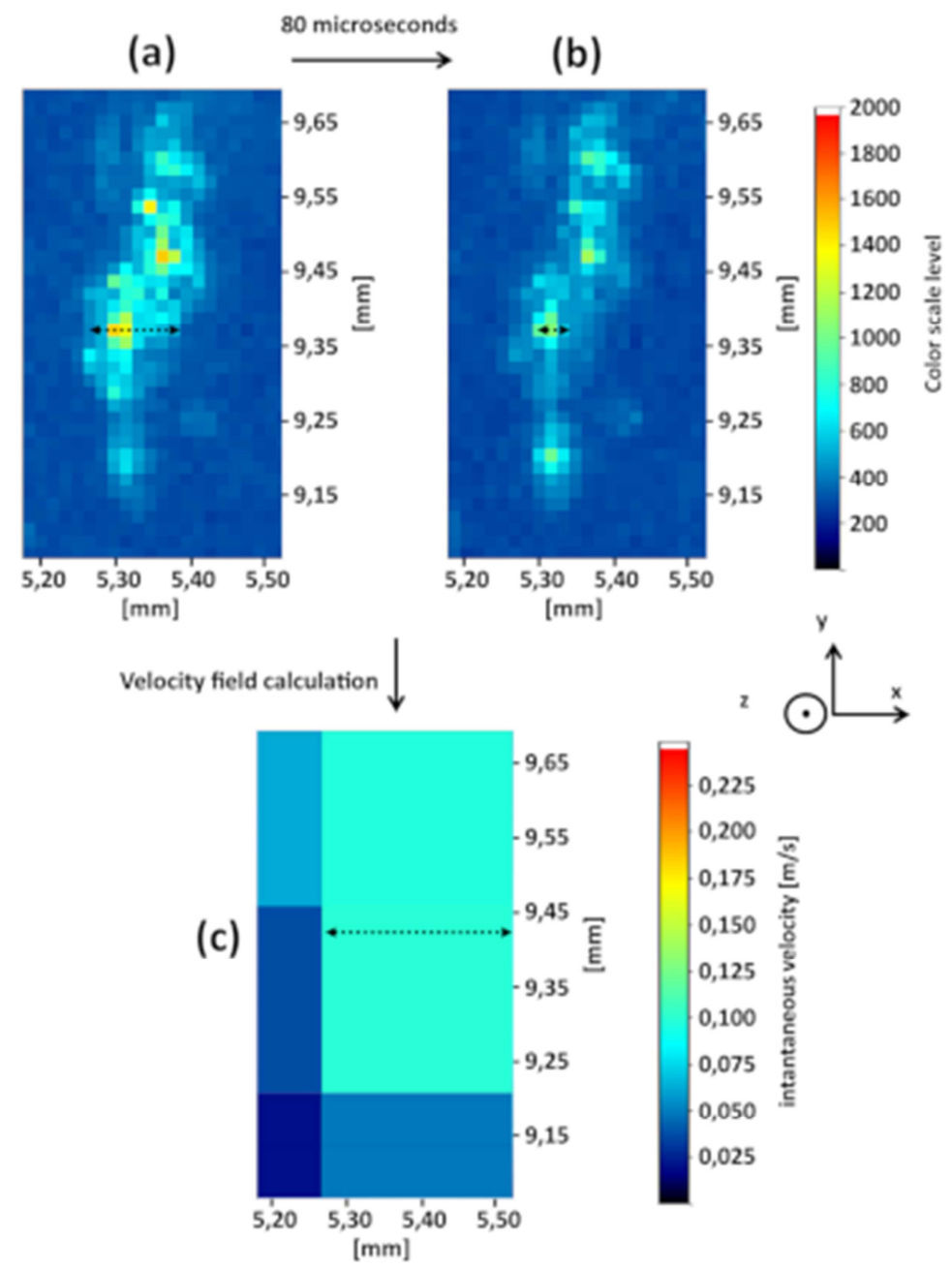

Fig. 10: PIV doublet recording a bubble cluster collapse and resulting instantaneous velocity field within the canal. Reynolds $=900$, flow velocity $=0.020 \mathrm{~m} / \mathrm{s}$, time between two images of a doublet $=80$ microseconds. Pixel size on doublet images $=16.5 * 16.5 \mu \mathrm{m}^{2}$ and interrogation window size on velocity field $=264 * 264 \mu \mathrm{m}^{2}$.

As already aforementioned, some previous studies have established a clear relationship not only between acoustic cavitation and turbulences increase $[3,10]$ but also between bubble collapse and recirculation flows around bubbles walls [5]. Consequently, it seems reasonable to link the increase of turbulent kinetic energy in the presence of $25 \mathrm{kHz}$ ultrasound (Fig. 11) to the collapses and oscillations of bubbles and bubble clusters (Fig. 10). Whatever the set mean flow velocity in the presence of $25 \mathrm{kHz}$ ultrasound, turbulent kinetic energy increases as compared to silent regime. Nevertheless, highest values are measured close to the heating wall 
and for the highest flow velocity where the turbulent kinetic energy can reach locally up to $0.15 \mathrm{~m}^{2} / \mathrm{s}^{2}$ (Fig. 11). Turbulent kinetic energy mean values within the bulk are overall similar for all experimental flow conditions and are equal to $0.014 \mathrm{~m}^{2} / \mathrm{s}^{2}$ (see Fig. 11). This means that acoustic cavitation can induce strongest turbulence rates near the heating wall. This observation is consistent with the fact that acoustic cavitation bubble collapse is known to be more violent when occurring near a solid wall [5]. Bubbles behavior is driven by the ultrasonic frequency and power, liquid properties such as viscosity, surface tension and vapor pressure and by the presence or not of solid wall. Any change in these parameters leads to the modification of bubbles size and collapsing diameter, oscillating frequency and strength of the collapse. Consequently, turbulent kinetic energy within the bulk remains constant whatever mean flow velocity. This observation is consistent with the unchanged operating parameters influencing bubbles behaviors.

Fig. 11 also shows the increase of the turbulent kinetic energy values close to the heating wall as the flow velocity increases under $25 \mathrm{kHz}$ ultrasonic field. This substantial increase can be explained by taking into account the laminar boundary layer thickness and the size of fluid area disturbed by cavitation bubbles. The disturbed fluid area size (linked to the one of collapsing bubbles and clusters as shown in Fig. 10) is estimated as an example by $\chi$ in Fig. 12. $\chi$ is dependent on several aforesaid parameters but not on the flow regime in contrary to the boundary layer thickness ( $\delta$ in Fig. 12) which decreases as mean flow velocity and Reynolds number increase. The velocity spots size $(\chi)$ distribution is ranging from 250 micrometers to 500 micrometers, i.e. one or two PIV interrogation windows (squares in Fig. 12). This size distribution was observed for all mean flow velocities tested in this study. The flow velocity within the canal does not influence the velocity spots size nor their spatial distribution. Because the boundary layer thickness decreases as flow velocity and associated Reynolds increase, the ratio $\chi / \delta$ increases for the same conditions. Consequently, the 
disturbance effect within the boundary layer due to bubbles collapse increases as mean flow

424 velocity and Reynolds number increase. Indeed, violent collapse of bubbles literally disrupts 425 the boundary layer, laminar flow being turned into a very turbulent one over a thickness 426 defined by $\chi$. This value is driven by the collapse strength of the bubble and by viscous 427 effects whose attenuate disturbance propagation. The smaller the thickness of the boundary 428 layer is (i.e. the higher flow velocity and Reynolds number are), the easier bubbles are able to 429 disrupt it over all its thickness It seems relevant to say that this phenomenon leads to the 430 increase of the heat transfer enhancement with respect to flow rate increase.

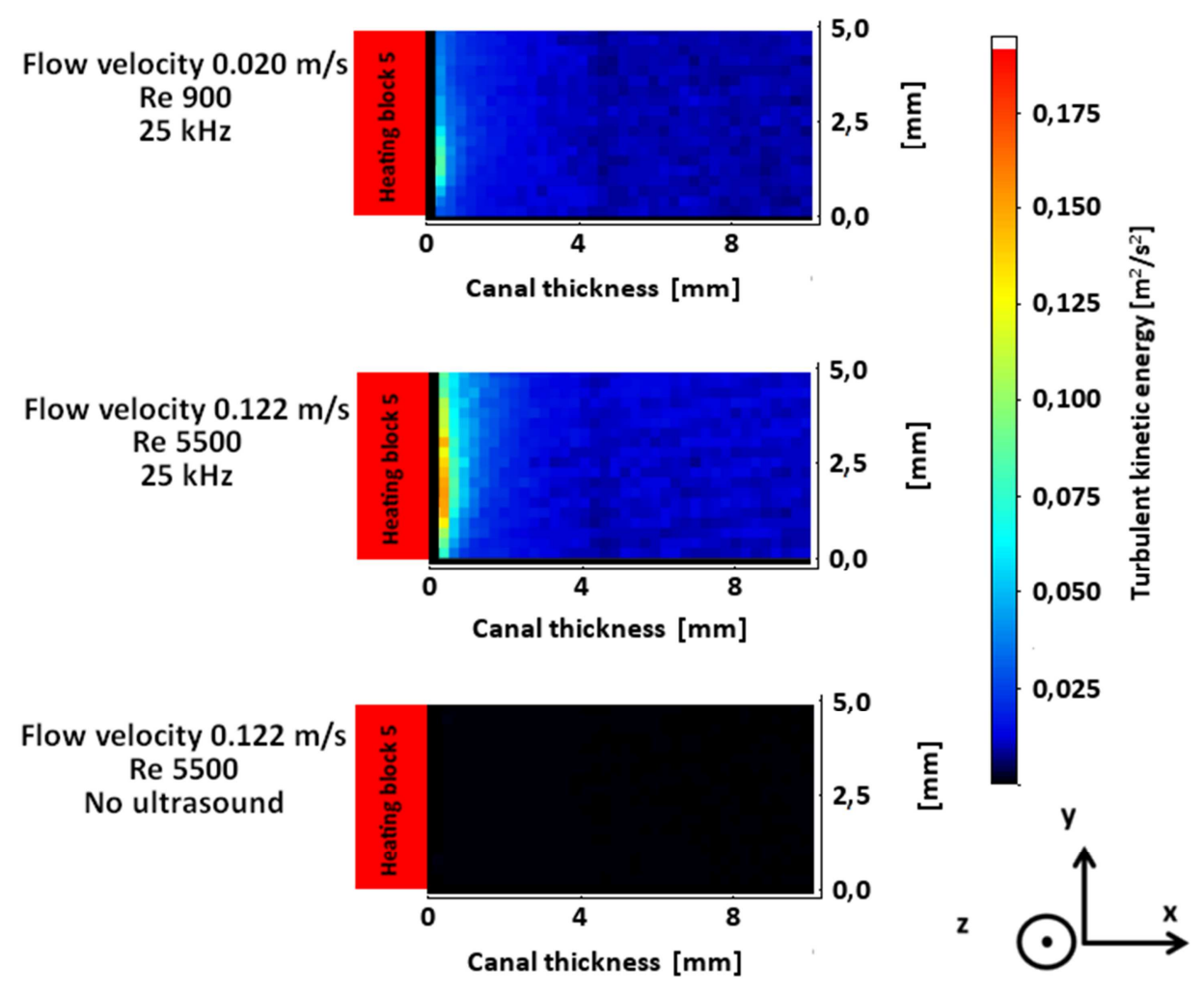

Fig. 11: Details of Turbulent Kinetic Energy (TKE) field near the $5^{\text {th }}$ heating block from 0 to $10 \mathrm{~mm}$ from the heating wall to the bulk and on the first five millimeters in height under $25 \mathrm{kHz}$ ultrasound sonication and silent regime for mean flow velocity $=0.020$ and $0.122 \mathrm{~m} / \mathrm{s}$ corresponding to Reynolds $=900$ and 5500. 


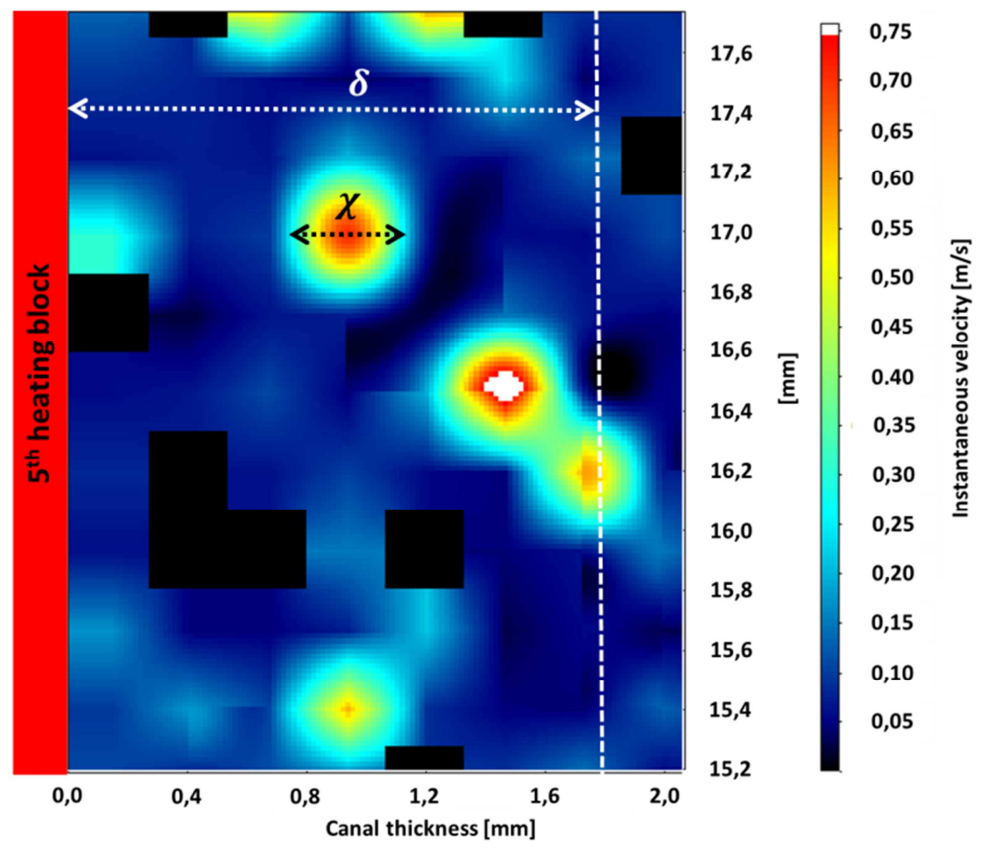

Fig. 12: Illustration of the influence area of cavitation bubbles on the laminar boundary layer. The theoretical viscous boundary layer $\delta$ for silent regime is calculated from [45] ( $f=25 \mathrm{kHz}$, $\mathrm{e}=30 \mathrm{~mm}, \mathrm{Q}_{\mathrm{v}}=1075 \mathrm{~L} / \mathrm{h}$, Mean flow velocity $=0.099 \mathrm{~m} / \mathrm{s}, \mathrm{Re}=4500, \delta=1.76 \mathrm{~mm}, \mathrm{P}_{\mathrm{us}}=$ $110 \mathrm{~W})$.

\subsection{Thermo-hydraulic study between $25 \mathrm{kHz}$ and 2 MHz sonication}

As already shown in this paper, thermal and hydrodynamic behaviors at $25 \mathrm{kHz}$ and $2 \mathrm{MHz}$ sonication are different. Moreover, in Fig. 13, average turbulent kinetic energy values are

434 plotted for both frequencies with mean flow velocities equal to 0.020 and $0.122 \mathrm{~m} / \mathrm{s}(\operatorname{Re}=900$ and 5500 respectively) as a function of canal position. These calculated values give the mean

436 value for each interrogation window column (y-axis) for a fixed row (x-axis) in order to 437 obtain an average turbulent kinetic energy profile with respect to canal thickness (x-axis).

438 This leads to quantitative values required to compare hydrodynamic effects for each ultrasound frequency. 
As illustrated in Fig. 13, for $2 \mathrm{MHz}$ ultrasound the lower the mean flow velocity is, the higher

441 the average turbulent kinetic energy is. This observation is in agreement with the Nusselt

442 number behavior, which experiences a decrease when flow velocity and thereby Reynolds

443 number increase (Fig. 4). This naturally leads to a decrease of the Heat Transfer Enhancement

444 Factor (HTEF) as plotted in Fig. 14.

445 With $25 \mathrm{kHz}$ sonication, average turbulent kinetic energy values of Fig. 13 are also in good 446 agreement with TKE fields presented in Fig. 11. The highest values are obtained close to the heating wall whatever the mean flow velocity. The higher the mean flow velocity is, the higher the turbulent kinetic energy near the wall is. Nevertheless, whatever the considered flow velocity, the turbulent kinetic energy profile remains unchanged. Indeed, when going far from the heating wall, i.e. at a distance higher than $4 \mathrm{~mm}$ (x-axis), a nearly constant value of the average TKE is measured within the bulk. Consequently, $25 \mathrm{kHz}$ ultrasound modifies bulk turbulences whatever the mean flow velocity value, allowing a constant mixing effect within the bulk of the liquid. This could be of great interest for processes that require constant mixing effects of the fluid within the bulk on large flow velocity range.

However, the thermal enhancement increase, with respect to the mean flow velocity increase observed for $25 \mathrm{kHz}$ sonication (Fig. 14), is also consistent with the $\chi / \delta$ ratio increase with same operating conditions. Indeed, the increase of the mean flow velocity and associated Reynolds number induces a decrease of the boundary layer thickness. This phenomenon increases the disruption effect due to cavitation bubbles on the laminar boundary layer. By consequence, heat transfer from the heating wall to the bulk increases leading to a Nusselt number increase. Therefore, it can be expected that when the ratio $\chi / \delta$ tends towards one, Nusselt number would not increase anymore with respect to the mean flow velocity. This could explain the asymptotical behavior for experimental curves observed for both Nusselt number (see Fig. 4) and HTEF profiles (see Fig. 14). As a conclusion, it is of great importance 
to highlight that using $25 \mathrm{kHz}$ ultrasound will be preferable to enable optimum intensification

466 of the transfer process under transitory-turbulent flows for processes involving parietal 467 transfer such as heat exchangers or membrane processes.

468 One can remark that the laminar boundary layer thickness is also decreasing with respect to 469 Reynolds number increase for $2 \mathrm{MHz}$ sonication. So why is this behavior different from the 470 one observed with $25 \mathrm{kHz}$ sonication at high flow velocity? It is probable that increasing the 471 pressure fluctuations or the flow velocity can affect the wave propagation and then the streaming production at $2 \mathrm{MHz}$. Thus, the acoustic streaming is weaker for high Reynolds numbers. This induces less intense convective effects and turbulence kinetic energy values for

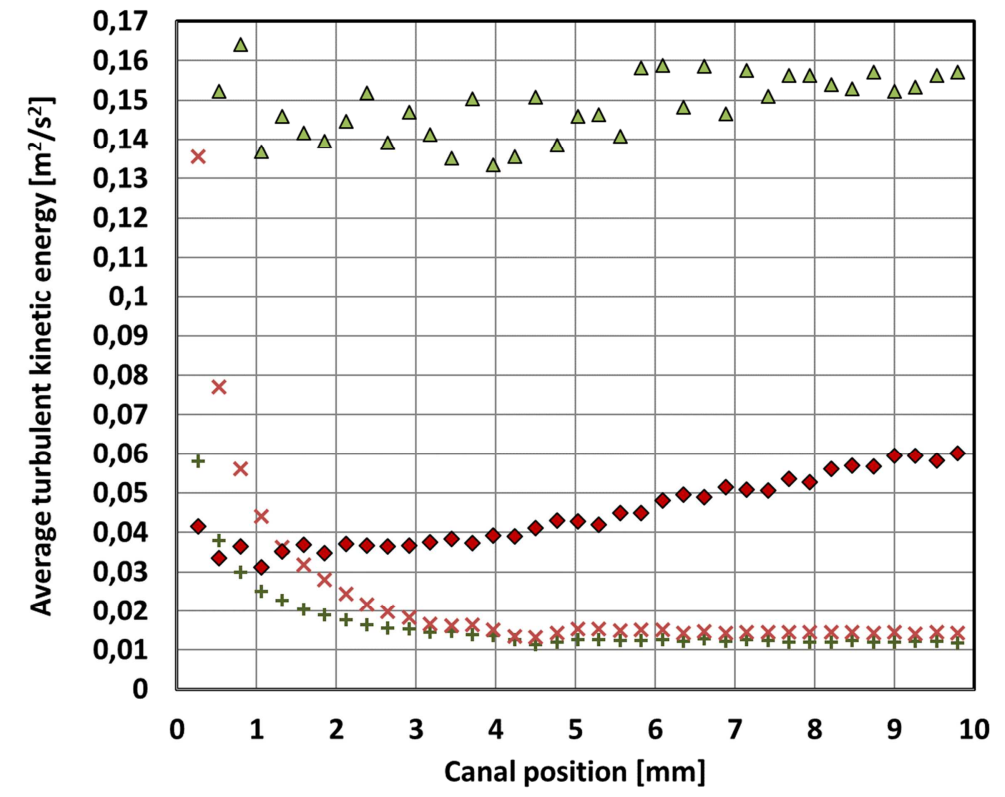

+ Flow velocity $0.020 \mathrm{~m} / \mathrm{s}(\operatorname{Re} 900) 25 \mathrm{kHz} \times$ Flow velocity $0.122 \mathrm{~m} / \mathrm{s}(\operatorname{Re} 5500) 25 \mathrm{kHz}$

$\Delta$ Flow velocity $0.020 \mathrm{~m} / \mathrm{s}(\operatorname{Re} 900) 2 \mathrm{MHz} \diamond$ Flow velocity $0.122 \mathrm{~m} / \mathrm{s}(\operatorname{Re} 5500) 2 \mathrm{MHz}$

Fig. 13: Average turbulent kinetic energy profile vs canal position on the first 10 millimeters from the $5^{\text {th }}$ heating block to the bulk (x-axis) under $25 \mathrm{kHz}$ and $2 \mathrm{MHz}$ sonication for mean flow velocity $=0.020$ and $0.122 \mathrm{~m} / \mathrm{s}$ corresponding to $\mathrm{Re}=900$ and 5500. 
475 When average turbulent kinetic energy curves are compared with respect to frequency for

476 fixed hydrodynamic conditions, it appears that $2 \mathrm{MHz}$ ultrasound produces a higher level of

477 turbulence at low mean flow velocities near the heating wall (Fig. 13). The contrary occurs at

478 high flow velocities. This observation is consistent with thermal results both expressed in 479 terms of Nusselt numbers (Fig. 4) or in terms of Heat Transfer Enhancement Factor (Fig. 14).

480 Indeed, the highest Nusselt Number and HTEF values at the lowest liquid flow rate are obtained with $2 \mathrm{MHz}$ ultrasound while the contrary is observed at highest flow velocity under $25 \mathrm{kHz}$ sonication.

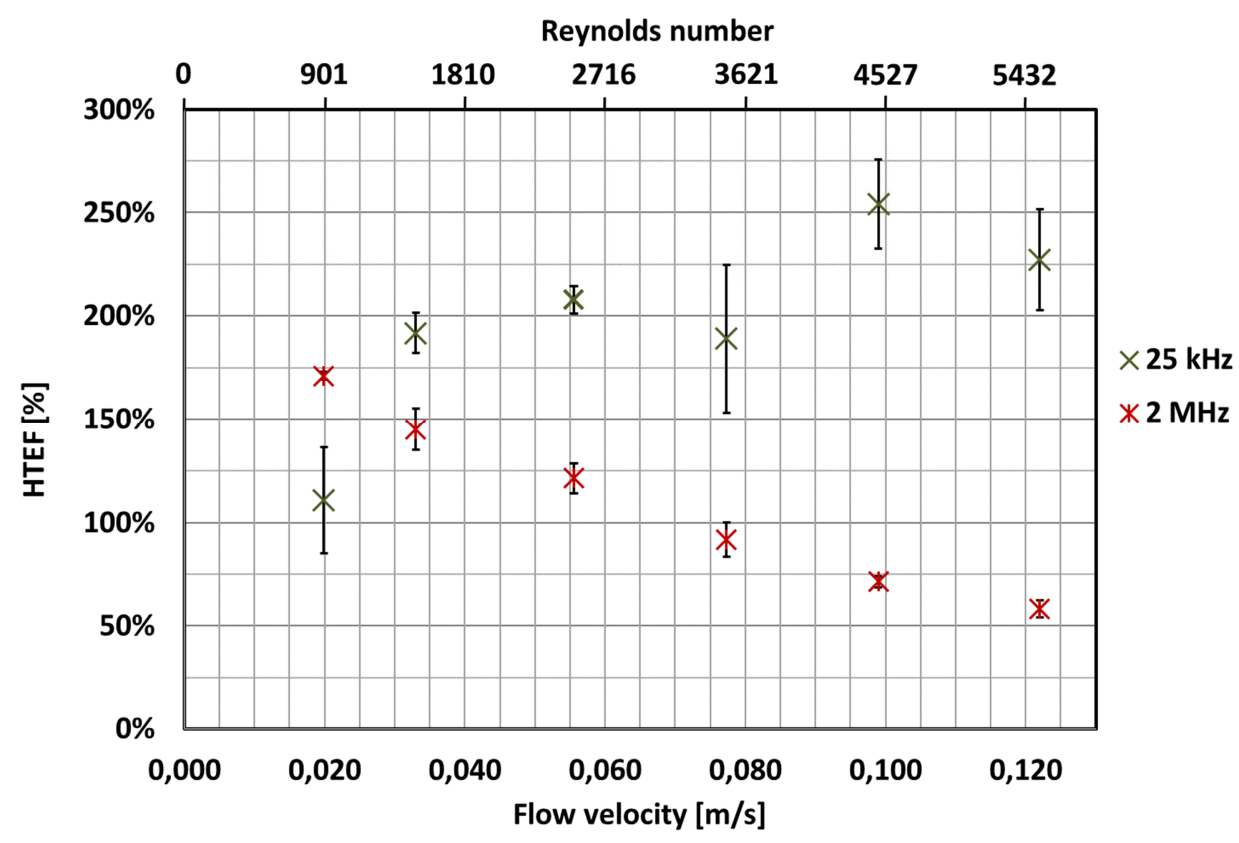

Fig. 14: Heat Transfer Enhancement Factor vs Reynolds number and mean flow velocity for $25 \mathrm{kHz}$ and $2 \mathrm{MHz}$ ultrasound. Total ultrasound power is equal to $110 \mathrm{~W}$, total heating power is equal to $450 \mathrm{~W}$.

Fig. 15 is finally suggested as a qualitative illustration of the relationship between hydrodynamic and thermal behavior for each frequency investigated in this study. For $2 \mathrm{MHz}$ sonication, an increase of mean flow velocity leads to a decrease of the turbulent kinetic 
488 boundary layer thickness, with respect to the mean flow velocity, induces an increase of the disruption effect of the boundary layer produced by acoustic bubbles collapse. This leads to a decrease of the thermal resistance and therefore in an increasing thermal enhancement as flow

491 velocity increases.

492 It is therefore reasonable to make the hypothesis that for a fixed ultrasonic power, acoustic 493 streaming is more efficient to enhance parietal transfer under laminar flow regimes while acoustic cavitation is more relevant under transitory-turbulent flows.

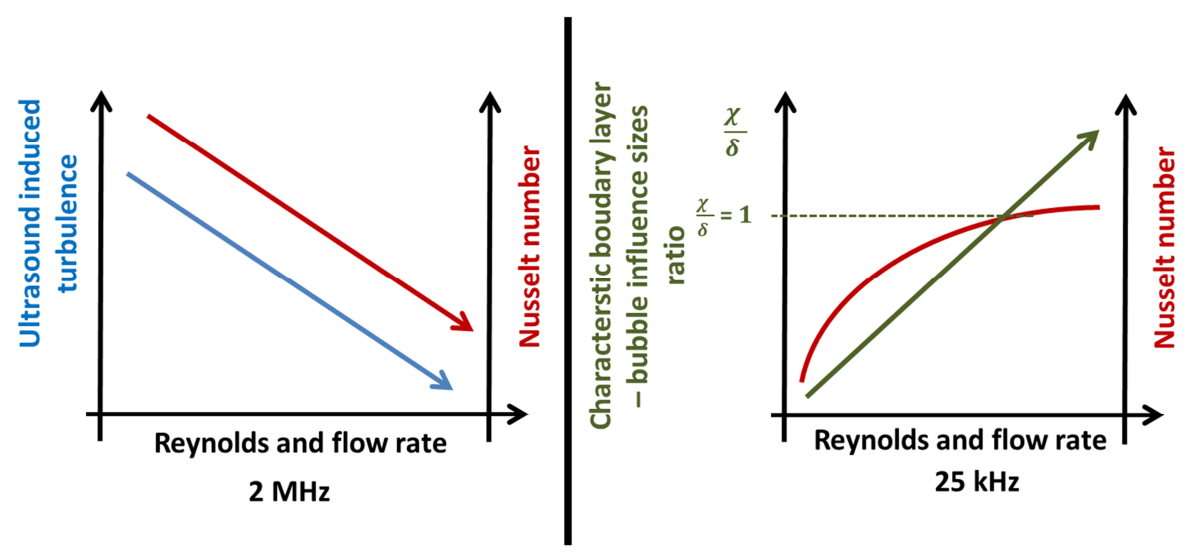

Fig. 15 : Illustration of the phenomenon involved in heat transfer enhancement by ultrasound in presence of acoustic streaming $(2 \mathrm{MHz})$ and acoustic cavitation $(25 \mathrm{kHz})$.

\section{Conclusions}

The aim of this work, which belongs to a heat exchangers optimization project, was to study mechanisms involved and responsible of the intensification of heat transfer with two different ultrasound frequencies. One of the objectives was to establish a link between observed acoustically induced heat transfer enhancements and related induced hydrodynamic phenomena depending on the experimental conditions. This work focused on a comparison 
between the differences highlighted using low $(25 \mathrm{kHz})$ or high $(2 \mathrm{MHz})$ frequency from both thermal and hydrodynamic points of view.

Thermal enhancement by ultrasound, i.e. Nusselt number increase compared to silent condition, is observed for both frequencies. On the one hand, $2 \mathrm{MHz}$ ultrasound frequency produces strong convective effect usually named acoustic streaming that induces turbulence enhancement and global mixing effect. On the second hand, acoustic cavitation produced by $25 \mathrm{kHz}$ ultrasound leads to an increase of turbulences both in the bulk and within the boundary layer. Highest values on turbulent kinetic energy are obtained near the heating wall (i.e. within the boundary layer) which is consistent with the fact that acoustic bubble collapse is more violent near a solid wall. The higher the mean flow velocity is, the higher the thermal

511 enhancement is. This stronger action of $25 \mathrm{kHz}$ ultrasound at high flow velocity could be 512 explained by the enhancement of the effect of cavitation bubbles collapse on the boundary layer. Indeed, as mean flow velocity increases, laminar boundary layer thickness decreases. This leads to an easier and a more efficient disruption of the boundary layer by bubble collapse and a reduction of the thermal resistance. In order to quantify this influence, a ratio defined as the size of the fluid disturbance area $\chi[\mathrm{m}]$ on the laminar boundary layer thickness $\delta[\mathrm{m}]$ can be estimated. When this ratio $\chi / \delta$ is equal to 1 , it means that the length of disturbance area produced by bubbles collapse is equal to boundary layer thickness. This allows to directly transfer physical quantities (heat, concentration...) from the wall to the bulk flow. It is then expected that when the ratio $\chi / \delta$ is equal or superior to 1 , Nusselt number may stop to increase with respect to mean flow velocity for $25 \mathrm{kHz}$ ultrasound regime.

522 Further studies will prospect the boundary layer disruption explanation proposed here with experiments performed for higher flow velocities and Reynolds numbers. Additional work will aim at determining causes of the turbulence attenuation with respect to flow velocity and 
525 Reynolds number increase in presence of $2 \mathrm{MHz}$ ultrasound observed in this study. The

526 objective would be to determine if this phenomenon is reliable to the increase of the Reynolds

527 number, i.e. to the natural turbulence in the flow in silent regime, or to the increase of the

528 mean flow velocity. A Reynolds similarity study, including canal thickness modification for

529 fixed Reynolds values, and then different flow velocities should help to answer to this

530 question. Finally, a study dealing with global energy balance of thermal enhancement by

531 ultrasound should be done. A comparison between energy efficiency of such a device and

532 passive methods could be of great interest. Nevertheless, this kind of study needs an

533 optimization of the ultrasound technology in accordance with thermal enhancement goals.

534 At least, results reported in this paper provide a better understanding of thermal intensification

535 by using low $(25 \mathrm{kHz})$ or high $(2 \mathrm{MHz})$ frequency ultrasound according to main

536 hydrodynamic phenomena induced by acoustic cavitation and acoustic streaming. It is hoped

537 that this work will be helpful to the way to the design of future vibrating heat exchangers. 


\section{References}

[1] T. Mason, J. Lorimer, Applied sonochemistry: Uses of power ultrasound in chemistry and processing, New York: Wiley-VCH, 2002. DOI: 10.1002/352760054X

[2] A. Peshkovsky, S. Peshkovsky, Acoustic cavitation theory and equipment design principles for industrial applications of high-intensity ultrasound, N. Science, Éd., New York, 2010. ISBN-10: 1617610933

[3] S. Nomura, Y. Sasaki, K. Murakami, Flow pattern in a channel during application of ultrasounic vibration, Japanese Journal of Applied Physics 39 (8) (2000) 4987-4989. DOI: 10.1143/JJAP.39.4987

[4] L. Landau, E. Lifshitz, Physique théorique - Mécanique des fluides, vol. 6, MIR, 1966.

[5] T.G. Leighton, The acoustic bubble, Londre: Academic press, 1994. ISBN-10: 0-12441920-8

[6] A. Mandroyan, R. Viennet, Y. Bailly, M.L. Doche, J.Y. Hihn, Modification of the ultrasound induced activity by the presence of an electrode in a sonoreactor working at two low frequencies (20 an $40 \mathrm{kHz}$ ). Part I: Active zone visualisation by laser tomography, Ultrasonics Sonochemistry 16 (1) (2009) 88-96. DOI: 10.1016/j.ultsonch.2008.05.003

[7] G. Mazue, R. Viennet, J.Y. Hihn, D. Bonnet, M. Barthes, Y. Bailly, I. Albaïna, Influence of a Perpendicular Liquid Flow on a Cleaning Process using $20 \mathrm{kHz}$ ultrasound characterisation of the agitation at vicinity of the surface opposite to the transducer, The Canadian Journal of Chemical Engineering 93 (2) (2015) 201-205. DOI: 10.1002/cjce.22079

[8] P. Bru, O. Bulliard-Sauret, R. Couturier, System and method of ultrasonic cleaning of a soiled surface, comprising an ultrasonic wave generation device. World Brevet WO 2016/046278 A1, 31-03-2016

[9] S. Nomura, K. Murakami, M. Kawada, Effects of Turbulence by Ultrasonic Vibration on 
Fluid Flow in a Rectangular Channel, Japanese Journal of Applied Physic 41 part 1 (11A) (2002) 6601-6605.

[10] O. Bulliard-Sauret, $\mathrm{PhD}$ thesis: Étude expérimentale de l'intensification des transferts thermiques par les ultrasons en convection forcée, Grenoble, France, 2016.

[11] O. Bulliard-Sauret, S. Ferrouillat, L. Vignal, E. Pashmi, A. Memponteil, N. Gondrexon, Experimental study of heat transfer enhancement using ultrasound on a flat plate in forced convection, 8th Turbulence Heat and Mass Transfer conference (THMT-15), Sarajevo; Bosnia and Herzegovina, 2015.

[12] C. Eckart, Vortices and streams caused by sound waves, Physical Review 73 (11) (1948). DOI: 10.1103/PhysRev.73.68

[13] M. Wiklund, R. Green, M. Ohlin, Acoustofluidics 14: Applications of acoustic streaming in micro fluidic devices, Lab Chip, 12 (2012) 2438-2451. DOI: 10.1039/c2lc40203c

[14] A.R. Wiliams, J.S. Slade, Ultrasonic dispersal of aggregates of Sarcina lutea, Ultrasonics, 9 (2) (1971) 85-87. DOI: 10.1016/0041-624X(71)90123-5

[15] M.K. Atkas, B. Farouk, Y. Lin, Heat Transfer Enhancement by acoustic streaming in an enclosure, Journal of Heat Transfer 127 (12) (2005) 1313-1321. DOI: 10.1115/1.2098858

[16] B. Moudjed, V. Botton, D. Henry, S. Millet, J.P. Garandet, H. Ben-Hadid, Oscillating acoustic streaming jet, Applied Physics Letters 105 (18) (2014). DOI: $10.1063 / 1.4901319$

[17] N. Gondrexon, V. Renaudin, C. Petrier, M. Clement, P. Boldo, Y. Gonthier, A. Bernis, Experimental study of the hydrodynamic behaviour of a high frequency ultrasonic reactor, 5 (11) (1998). DOI: 10.1016/S1350-4177(97)00043-6

[18] H. Monnier, A.M. Wilhelm, H. Delmas, Influence of ultrasound on mixing on the molecular scale for water and viscous liquids, Ultrasonics Sonochemistry (6) (1-2) (1999) 67-74. DOI: 10.1016/S1350-4177(98)00034-0

[19] M. Legay, N. Gondrexon, S. Le Person, P. Boldo, A. Bontemps, Enhancement of heat transfer by ultrasound: Review and recent advances, International Journal of Chemical 


\section{Engineering 2011 (2011). DOI: 10.1155/2011/670108}

[20] T. Boziuk, M. Smith, A. Glezer, Enhanced Boiling Heat Transfer on Micromachined Surfaces using acoustic actuation, Thermal and Thermomechanical Phenomena in Electronic Systems conference, Las Vegas, NV, USA, 2016.

[21] M. Zheng, B. Li, Z. Wan, B. Wu, Y. Tang, J. Li, Ultrasonic heat transfer enhancement on different structural tubes in LiBr solution, Applied Thermal Engineering 106 (2016) 625633. DOI: 10.1016/j.applthermaleng.2016.06.019

[22] V. Uhlenwinkel, R. Meng, K. Bauckhage, Investigation of heat transfer from circular cylinders in high power $10 \mathrm{kHz}$ and $20 \mathrm{kHz}$ acoustic resonant fields, International Journal of Thermal Science 39 (8) (2000) 771-779. DOI: 10.1016/S1290-0729(00)00270-2

[23] Y. Chen, S. Sun, Y. Lai, C. Ma, Influence of ultrasound to convectional heat transfer with fouling of cooling water, Applied Thermal Engineering 100 (2016) 340-347. DOI: 10.1016/j.applthermaleng.2016.01.144

[24] N. Gondrexon, Y. Rousselet, M. Legay, P. Boldo, S. Le Person, A. Bontemps, Intensification of heat transfer process: Improvement of shell-and-tube heat exchanger performances by means of ultrasound, Chemical Engineering and Processing: Process Intensification 49 (9) (2010) 936-942. DOI: 10.1016/j.cep.2010.06.007

[25] H.K. Tam, L.M. Tam, A.J. Ghajar, I.P. Chen, Experimental study of the ultrasonic effect on heat transfer inside a horizontal mini-tube in the laminar region, Applied Thermal Engineering, 114 (2017) 1300-1308. DOI: 10.1016/j.applthermaleng.2016.09.166

[26] Y. Tisseau, P. Boldo, N. Gondexon, A. Bontemps, Conception et étude préliminaire d'un échangeur de chaleur tubes et calandre assisté par ultrasons, 18ème Congrès Français de Mécanique conference, Grenoble, France, 2007

[27] O. Bulliard-Sauret, S. Ferrouillat, L. Vignal, A. Memponteil, N. Gondrexon, Heat transfert enhancement using $2 \mathrm{MHz}$ ultrasound, Ultrasonics Sonochemistry 39 (2017) 262-271. DOI: 10.1016/j.ultsonch.2017.04.021

[28] U. Kurbanov, K. Melkumov, Use of ultrasound for intensification of heat transfer process 
in heat exchangers, Proceedings of the International Congress of Refrigeration, Washinton D.C., USA, 2003.

[29] X. L. Duan, X. Y. Wang, G. Wang, Y. Z. Chen, X. Q. Qiu, Experimental study on the influence of ultrasonic vibration on heat transfer and pressure drop in heat exchanger tubes, Petrochem. Equip 33 (11) (2004) 1-4.

[30] Y. Yao, X. Zhang, Y. Guo, Experimental Study on Heat Transfer Enhancement of Waterwater Shell-and-Tube Heat Exchanger Assisted by Power Ultrasonic, International Refrigeration and Air Conditioning conference, Purdu University,West Lafayette, Indiana, USA, 2010.

[31] Y. Yao, Research and applications of ultrasound in HVAC field: A review, Renewable and Sustainable Energy Reviews 58 (2016) 52-68. DOI: 10.1016/j.rser.2015.12.222

[32] M. Barthès, G. Mazue, D. Bonnet, R. Vionnet, J.Y. Hihn Y. Bailly, Characterization of the activity of ultrasound emitted in a perpendicular liquid flow using Particle Image Velocimetry (PIV) and electrochemical mass tranfer measurements, Ultrasonics 59 (2015) 72-78. DOI: 10.1016/j.ultras.2015.01.015

[33] S. Nomura, K. Murakami, Y. Sasaki, Streaming induced by ultrasonic vibration in a water vessel, Japanese Journal of Applied Physics 39 (16A) (2000) 3636-3640. DOI: 10.1143/JJAP.39.3636

[34] D.R. Lee, B. Loh, Smart cooling technology utilizing acoustic streaming, Institute of Electrical and Electronics Engineers Transaction on Components and Packaging Technologies (IEEE) 30 (4) (2008) 691-699. DOI: 10.1109/TCAPT.2007.901756

[35] H. Yukawa, H. Saito, T. Hoshino, Effect of ultrasonic vibration on free convection heat transfer from an inclinate plate in water, Heat Transfer 5 (11) (1976) 37-49 / Originaly published in Kagaku Kogaku Ronbunshu 1 (3) (1975) 229-234. DOI: 10.1252/kakoronbunshu.1.229

[36] B. Moudjed, V. Botton, D. Henry, S. Millet, J. P. Garandet, H. Ben Hadid, Near-field acoustic streaming jet, Physical Review, E 91 (2015). DOI: 


\subsection{3/PhysRevE.91.033011}

[37] M. Legay, B. Simony, P. Boldo, N. Gondrexon, S. Le Person, A. Bontemps, Improvement of heat transfer by means of ultrasound: Application to a double tube heat exchanger, Ultrasonics $\quad$ Sonochemistry, $19 \quad$ (2012) 1194-1200. DOI: 10.1016/j.ultsonch.2012.04.001

[38] B. Moudjed, V. Botton, D. Henry, H. Ben Hadid et J.P. Garandet, Scaling and dimensional analysis of acoustic streaming jet, Physics of Fluids 26 (2014). DOI: $10.1063 / 1.4895518$

[39] O. Louisnard, A viable method to predict acoustic streaming in presence of cavitation, Ultrasonics Sonochemistry, 35 Part A $\quad$ (2017) 518-524. DOI: 10.1016/j.ultsonch.2016.09.013

[40] M. Talebi, M. Setareh, M. Saffar-Avval, R.H. Abardeh, Numerical investigation of natural convection heat transfer in a cylindrical enclosure due to ultrasonic vibrations, Ultrasonics 76 (2017) 52-62. DOI: 10.1016/j.ultras.2016.12.010

[41] H. Kiani, Z. Zhang, D.W. Sun, Experimental analysis and modeling of ultrasound assisted freezing of potato spheres, Ultrasonics Sonochemistry 26 (2015) 321-331. DOI: 10.1016/j.ultsonch.2015.02.015

[42] M. Legay, Y. Allibert, N. Gondrexon, P. Boldo, S. Le Person, Experimental investigations of fouling reduction in an ultrasonically-assisted heat exchanger, Experimental Thermal and Fluid Science 46 (2013) 111-119, 2013. DOI: 10.1016/j.expthermflusci.2012.12.001

[43] LaVision, Product Manual DaVis 8.3 Software, Göttingen, 2015.

[44] S. Kakaç, R. Shah, W. Aung, Handbook of convective heat transfer, Wiley-interscience, 1987. ISBN-10: 0471817023

[45] R. Joulié, Mécanique des fluides appliquée, Ellipse, 1998. ISBN-10: 2-7298-6768-6 